\title{
Computational mate choice: Theory and empirical evidence
}

\author{
Sergio Castellano ${ }^{\mathrm{a}, *}$, Giorgia Cadeddu ${ }^{\mathrm{a}}$, Paolo Cermelli ${ }^{\mathrm{b}}$ \\ a Dipartimento di Biologia Animale e dell'Uomo, Via Accademia Albertina, 13, Università di Torino, Torino 10123, Italy \\ b Dipartimento di Matematica, Via Carlo Alberto, 10, Università di Torino, Torino, Italy
}

\section{A R T I C L E I N F O}

\section{Article history:}

Received 25 August 2011

Received in revised form 17 February 2012

Accepted 26 February 2012

\section{Keywords:}

Sexual selection

Preference function

Mate copying

Decision making

Bayes' theorem

Sequential sampling models

Mate searching tactics

\begin{abstract}
A B S T R A C T
The present review is based on the thesis that mate choice results from information-processing mechanisms governed by computational rules and that, to understand how females choose their mates, we should identify which are the sources of information and how they are used to make decisions. We describe mate choice as a three-step computational process and for each step we present theories and review empirical evidence. The first step is a perceptual process. It describes the acquisition of evidence, that is, how females use multiple cues and signals to assign an attractiveness value to prospective mates (the preference function hypothesis). The second step is a decisional process. It describes the construction of the decision variable (DV), which integrates evidence (private information by direct assessment), priors (public information), and value (perceived utility) of prospective mates into a quantity that is used by a decision rule (DR) to produce a choice. We make the assumption that females are optimal Bayesian decision makers and we derive a formal model of DV that can explain the effects of preference functions, mate copying, social context, and females' state and condition on the patterns of mate choice. The third step of mating decision is a deliberative process that depends on the DRs. We identify two main categories of DRs (absolute and comparative rules), and review the normative models of mate sampling tactics associated to them. We highlight the limits of the normative approach and present a class of computational models (sequential-sampling models) that are based on the assumption that DVs accumulate noisy evidence over time until a decision threshold is reached. These models force us to rethink the dichotomy between comparative and absolute decision rules, between discrimination and recognition, and even between rational and irrational choice. Since they have a robust biological basis, we think they may represent a useful theoretical tool for behavioural ecologist interested in integrating proximate and ultimate causes of mate choice.
\end{abstract}

(C) 2012 Published by Elsevier B.V.

\section{Introduction}

An adult female that is looking for a mate, having survived to this stage, proves to have been a good decision maker. As a young, she made appropriate decisions about when to move and when to rest, where to go and where to avoid, and what and how to eat. But the positive fitness effects of these previous decisions could be suddenly nullified, if she now chooses the wrong mate. Indeed, mate choice is one of the most important decisions that females make in their life. For this reason, females are expected to have evolved a cognitive machinery that make them able to choose their mates effectively, by avoiding heterospecifics and by favouring discrimination between conspecifics of different qualities (Ryan, 1997; Ryan and Rand, 1993). Females usually base their mating decisions

\footnotetext{
* Corresponding author. Tel.: +39 116704547.

E-mail address: sergio.castellano@unito.it (S. Castellano).
}

on several males' signals or cues, which they perceive in either the same or different sensory modalities (Candolin, 2003; Partan and Marler, 1999). Since the information they acquire from these traits is always noisy and often conflicting, mating decisions are intrinsically uncertain and prone to errors (Johnstone and Grafen, 1992). To understand how mate choice evolved, we should thus understand how the uncertainty problem in mating decision has been solved.

Uncertainty in mating decisions depends on two factors. First, it depends on the amount of the information acquired. Normative models of mate choice typically focus on this aspect and try to find optimal economical rules of information gathering (Luttbeg, 1996, 2002; Real, 1990; Sullivan, 1994). But uncertainty depends also on the cognitive mechanisms of information processing, that is, on how several sources of information are integrated and used to reach a decision. Until recently, the cognitive aspects of mating decision have received scarce attention in sexual selection theory, because it was simplistically assumed that, if mate choice is 
advantageous to females, then selection will provide them with the way for choosing mates accurately. Bateson and Healy (2005), Castellano (2009a), Ryan et al. $(2007,2009)$ contended this view emphasizing the role of cognitive mechanisms for understanding the evolution of mate choice. Following the theoretical approach proposed by Marr (1982), Castellano (2009a) argued that sexual selection theory needs a computational theory of mate choice, a theory that could explain mating decisions at both the abstract level of the computational properties and at the proximate level of algorithm implementation. In the present paper, we move further along this path of inquiry, by presenting a computational model of mate choice and by reviewing empirical evidence in the light of this model.

Marr (1982) argued that the most general and abstract theory of an information-processing system (i.e. its computational theory) responds to the question of "what is being computed" and "why the computation is carried out". In mate choice, computation involves the perceived qualities (i.e. attractiveness) of prospective mates and it is carried out to select an appropriate male, given the amount of available uncertain evidence. Statistical theory predicts that an optimal decision process that wants to estimate the probability of an uncertain event must adopt a Bayesian approach. We thus make the adaptationist assumption that selection should have promoted the evolution of a Bayesian model of mating decision, that is, we assume that the computational theory of mate choice is based on the Bayesian computation of the posterior probability that a male is an appropriate mate (see Section 2).

Bayes' theorem has been often used by theoreticians in modeling animal behaviour (review in McNamara et al., 2006) and, in particular, mate choice (Collins et al., 2006; Lange and Dukas, 2009; Uehara et al., 2005) and there is empirical evidence that animals behave in a way consistent with the predictions of Bayesian updating models (Biernaskie et al., 2009; Mabry and Stamps, 2008; Valone, 2006). A Bayesian cognitive machinery of mating decision implies that female nervous system represents information about prospective mates in terms of conditional probability density functions. Recent studies in neuroscience provide evidence consistent with the hypothesis that perceptual computations in humans or non-human primates use these types of internal representations (Knill and Pouget, 2004) and that decisions arise by integrating information over time according to a Bayesian updating mechanism (Körding, 2007; Yang and Shadlen, 2007). It is not clear, however, to what extent these findings may be generalized to other animals with much simple nervous systems. In these species, females may rely on rules that are simpler and less computational demanding than Bayesian computations, but that result in decisions similar to those predicted by Bayesian updating strategies (Lange and Dukas, 2009).

In this paper we review patterns of mate choice and try to explain them in terms of their underlying mechanisms of information processing. We know a lot about mate choice. We know that mating decisions depend on mating preferences (Section 3) and that females make decisions on the basis of both private and public information (Section 4). We know that experience can affect mating decisions and that mate choice is often a highly plastic behaviour, which may be influenced by both the internal state and the external conditions in which choice is made (Section 4). We know that females may use different tactics for sampling and evaluating prospective mates and that choosing is often time consuming and accurate decisions require long evaluation sessions (Sections 5 and 6). We review all these phenomena within the unitary theoretical framework of the Bayesian model of mating decision. Although the entire theoretical building is based on the adaptationist assumption of optimal mate choice, we will not deal with optimality nor we will review theories and empirical evidence on the adaptive significance of mate choice. Our focus will be on the information-processing mechanisms of mate choice.

\section{The model of Bayesian decision making}

A Bayesian model of decision making is based on a comparison of posterior probabilities that certain events occur. Imagine a female that is evaluating a prospective mate to decide whether he is or is not an appropriate mate (Fig. 1, and see Glossary in Box 1 ).

\begin{tabular}{|c|c|c|c|}
\hline IS THE MALE APPROPRIATE? & IS THE & & IS THE MALE APPROPRIATE GIVEN HE IS ATTRACTIVE? \\
\hline Prior & Likelihood & Utility & Decision Variable \\
\hline
\end{tabular}

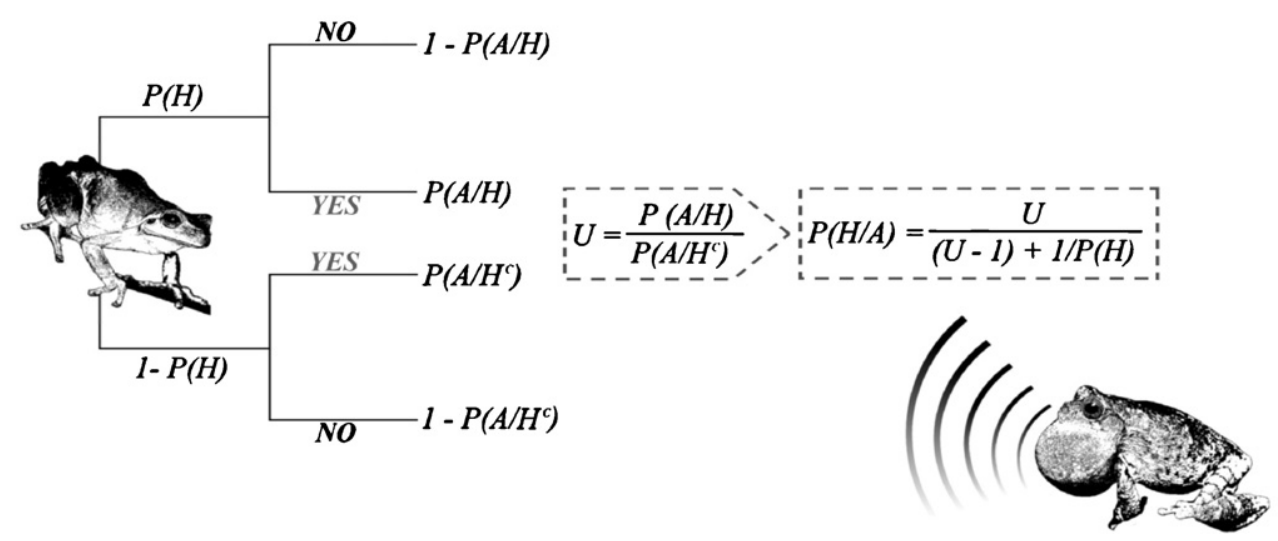

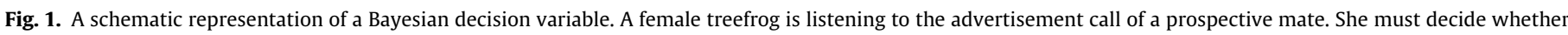

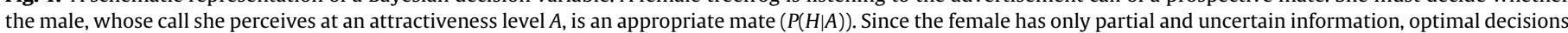

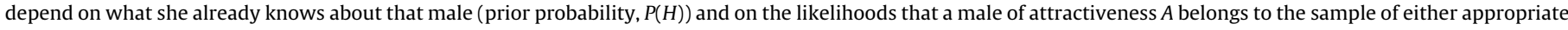

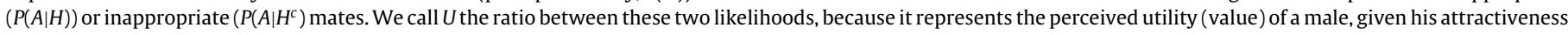
$A$. Bayes' rule explains how prior probabilities and likelihoods could be used to derive the posterior probability that this male is an appropriate mate $(P(H \mid A))$. 


\section{Box 1: Glossary}

Appropriateness (of a prospective mate) is the value of the decision variable. It is the posterior probability of considering a male an appropriate mate and depends on his perceived attractiveness, on his prior probability and on the internal and external conditions of the decision maker, which influence the perceived utility of the prospective mate.

Attractiveness (of a prospective mate) is defined by the preference function and depends only on perception. It represents a source of private information that is used by the decision variable during the evaluation process.

Choosiness is a component of mating preference, which does not depend on the private (i.e. the preference function) or public information (priors) on the prospective mate, but on the perceived utility of that male. Variation in choosiness is due to a variation in the utility function, which may result from a change of either the internal or the external conditions of the decision makers.

Decision rule determines how and when the decision variable is interpreted to arrive to a commitment to a particular choice. Decision variable is the synonym of appropriateness. It is the object responsible for the intragration of multiple piece of evidence over time.

Preference function defines the perceived attractiveness of a prospective mate on the basis of the signals and cues received by the decision maker.

Sequential sampling describes the dynamic of the decisional process, that is, the accommodation of multiple pieces of evidence over time. It includes two components: the decision variable, which integrates evidence over time, and the decision rule, which establishes when it is time to stop the process and to commit.

Utility function describes the relationship between the perceived attractiveness and the perceived utility of a prospective mate.

Utility is the level of uncertainty associated to the perceived attractiveness of a prospective mate and it is defined as the ratio between the conditional probability (likelihood) that the male is attractive given he is and given he is not an appropriate mate $\left(U=P(A \mid H) / P\left(A \mid H^{c}\right)\right)$. The utility is assumed to be a monotonic function of the perceived attractiveness.

Decision depends on the amount of evidence $(A)$ supporting the hypothesis $(H)$ that the prospective mate is an appropriate mate. Suppose that evidence depends on a set of male's traits $(x)$ so that, after evaluation, the amount of evidence the female has acquired is

$A=a(x)+\varepsilon$

where $a(x)$ represents the deterministic component of perception describing how the female integrates different sources of information encoded in $x$, whereas $\varepsilon$ is the stochastic component of perception, a normally distributed random variable with zero mean and variance $\sigma^{2}$ (Castellano, 2010; Phelps et al., 2006). Since the stochastic variable $A$ is consistent with the definition of "preference function" proposed by Jennions and Petrie (1997, p. 286 "the order in which an individual ranks prospective mates ceteris paribus"), we name the male perceived attractiveness $A$ as the female's preference function (PF).

According to the Bayes theorem, the probability that a male is an appropriate mate is given by the following formula:

$P(H \mid A)=\frac{P(A \mid H)}{P(A)} \times P(H)$

In words, the probability that $H$ is true, given a perceived attractiveness $A$, equals the probability that an appropriate mate is perceived at level $A(P(A \mid H))$ (i.e. the likelihood of $A$ in appropriate mates), times the prior probability that that male is an appropriate mate $(P(H))$, divided by the probability to perceive an advertising level $A$, independent of whether the male is or is not an appropriate mate $(P(A))$. This latter probability, $P(A)$, is the sum of the probabilities of perceiving $A$ when $H$ is either true $(P(A \mid H))$ or false $\left(P\left(A \mid H^{c}\right)\right)$ (where $H^{c}$ correspond to a non appropriate male).

$P(A)=P(A \mid H) \times P(H)+P\left(A \mid H^{c}\right) \times P\left(H^{c}\right)$

Imagine a female that has no previous information about the quality of a prospective mate, which she perceives of attractiveness $A$ (i.e. her prior probability being $P(H)=P\left(H^{c}\right)=0.5$ ). The probability that she will perceive this male as an appropriate mate increases with the increase of the ratio between the perceived probability of a correct assignment $(P(A \mid H))$ and the perceived probability of a false positive $\left(P(A \mid H)^{c}\right)$. For example, if $P(A \mid H)=0.9$ is much greater than $P(A \mid H)^{c}=0.3$ (their ratio being 3 ), then $P(A)=0.6$ and $P(H \mid A)=0.72$. In contrast, as the probability of a false negative increases (i.e. $P(A \mid H)^{c}=0.6$, the ratio being 1.5$), P(A)$ increases as well $(P(A)=0.75)$ and, consequently, the choice probability decreases $(P(H \mid A)=0.6)$. This simple numerical example should make clear that the effectiveness of a perceived signal $A(x)$ depends on the perceived probability that $x$ is emitted by both an appropriate and an inappropriate mate. In this sense, the ratio $U=P(A \mid H) / P\left(A \mid H^{c}\right)$ might be viewed as the perceived utility of the male and it is directly related to the perceived value of the information acquired (see Box 2 ).

\section{Box 2: Utility and information}

The utility function $u(A)$ is a measure of how the preference value $A$ is actually related to the appropriateness of the mate. In fact, when $u(A)=1$ and the likelihood of $A$ in an appropriate mate is the same as its likelihood in a non-appropriate mate, i.e., $P(A \mid H)=P\left(A \mid H^{c}\right)$, then $P(H \mid A)=P(H)$ and choice does not involve preference. For instance, when nothing is known about the male, $P(H)=1 / 2$ and choice is random. On the other hand, when $u(A)=0$, then $P(H \mid A)=0$ and the mate is refused with probability 1 .

Therefore, it is not surprising that the utility function is related to the information content $I(H, A)$ of the preference value $A$, that measures how the assignment of a preference value reduces the uncertainty of choice:

$I(H, A)=E(H)-E(H \mid A)$,

where $E(H)$ and $E(H \mid A)$ are the entropy of $H$ and the conditional entropy of $H$ given the preference $A$. Entropy is a measure of the uncertainty of a random variable that varies between 0 (no uncertainty) and 1 (maximum uncertainty): correspondingly, the information varies between -1 and 1 , and is negative when the preference increases the uncertainty of choice: for instance, $l(H, A)=0$ when $u(A)=1, l(H, A)$ is minimal (and non positive) when $u(A)=P\left(H^{c}\right) / P(H)$.

The first condition means that when $A$ is equally likely and $P(A \mid H)=P\left(A \mid H^{c}\right)$, preference does not entail any information gain. On the other hand, the condition $u(A)=P\left(H^{c}\right) / P(H)$ implies that choice is random with $P(H \mid A)=1 / 2$ : in this case, preference obviously increases the uncertainty in the selection process.

The perceived utility is the ratio between two conditional probabilities. For species with relatively simple nervous systems, however, such a calculation may be too computationally demanding to be carried out effectively. In these species, thus, selection may have favoured the evolution of much cheaper ways of representing the perceived utility of prospective mates. We, thus, make a further and important assumption. We assume that females directly translate sensory information (the perceived attractiveness) into likelihood ratio (i.e. the perceived utility), by means of a utility 
function (UF), $U=u(A)$, which increases monotonically with males' perceived attractiveness. Eq. (2) may be re-written as:

$P(H \mid A)=\frac{u(A)}{(u(A)-1)+\frac{1}{P(H)}}$

In the special case of no priors (i.e. $P(H)=0.5$ ), $P(H \mid A)=u(A) /(u(A)+1)$. As we will appear clear in Section 4.2, the distinction between preference and utility function is important if we assume that the perceived utility (value) of a prospective mate may depend not only on his perceived attractiveness (the quality of the sensory information), but also on the internal state and the external conditions of choosing females.

Eq. (4) defines the posterior probability $P(H \mid A)$. We name this element the Decision Variable (DV). The DV combines both evidence and priors into a quantity that is interpreted by a Decision Rule (DR) to produce a choice (Gold and Shadlen, 2007). According to this model, mate choice might be viewed as a three-step process: (1) the acquisition of evidence; (2) the evaluation of the prospective mate according to acquired evidence and priors; (3) the application of a Decision Rule to the Decision Variable. For each of these three steps, we review the theories that have been proposed and the empirical evidence that supports them.

\section{Acquisition of evidence: The computational mechanisms of perceived male attractiveness}

The preference function (Eq. (1)) describes how females convert the information of a prospective mate in an internal representation of his attractiveness. Implicitly, our model of mating decision assumes the perceived attractiveness $(A)$ to be a one-dimension variable, that is, it assumes females to order prospective mates along an ordinal scale of values. However, the internal representation of mate attractiveness might not be one-dimensional. Female mating decisions depend on several male traits, often involving different sensory modalities (reviews in Bro-Jorgensen, 2010; Candolin, 2003; Hebets and Papaj, 2005; Jennions and Petrie, 1997) and females may integrate these different sources of information in at least three different ways: (i) they may form a one-dimension representation of male attractiveness, as assumed by Eq. (1); (ii) they may form a multi-dimension representation of male attractiveness, but use a single decision variable (Knill and Pouget, 2004); or (iii) they may integrate different sources of information into different DVs, hierarchically ordered according to a priority rule (Candolin, 2003). Now, we consider the simple case in which females possess a one-dimension preference function and use a single DV in mating decision. In Section 7, we will return to this issue and we will consider the case of multi-dimension preference functions and the use of multiple DVs in mate choice.

\subsection{The preference function hypothesis}

The concept of "preference function" was first introduced by Lande (1981) to describe sexual selection on male traits. He defined a "preference function", $\psi(y, z)$, as the probability that a female with phenotype $y$ chooses a male of phenotype $z$. This definition, however, is more similar to our definition of decision variable (Eq. (2)) than to the Jennions and Petrie's (1997) definition of preference function (see Eq. (1)). Indeed, in sexual selection studies, the concepts of choice and preference have been often used as synonyms (Wagner, 1998), probably because the only way to empirically describe mating preferences is by observing mating decisions. Nevertheless, Wagner (1998) emphasizes the importance of keeping these two concepts distinct, because choice depends not only on mating preferences, but also on female sampling behaviour (i.e. 'choosiness' sensu Jennions and Petrie, 1997) and on the environmental conditions in which choice is carried out (Wagner, 1998). The Bayesian model of mate choice makes a clear distinction between preferences and choice and it also helps us to understand which are the assumptions that make it possible to derive patterns of preferences from observed patterns of choice. In fact, imagine a typical mate-choice experiment (i.e. recognition test, see below), in which we measure the conditional probability $C(H \mid x)$ that a stimulus $H$ of quality $x$ elicits a positive taxis in a receptive female. If females have no priors (i.e. $P(H)=0.5$ ) and if the probability of responding to a stimulus is the probability of perceiving it as appropriate (i.e. $C(H \mid x)=P(H \mid x)$ ), then, from Eq. (4), the perceived utility $u(A(x))$ (but notice, not the perceived attractiveness $A(x)$ ) is $u(A(x))=C(H \mid x) /(1-C(H \mid x))$. If the monotonic function between utility and attractiveness does not change both between and within females during the experiment, then the ranks of prospective mates along the preference and utility functions are the same.

The empirical study of mating preferences uses two experimental paradigms: the recognition test and the comparative choice (review in Wagner, 1998). In a recognition test, females are exposed to one stimulus at a time (no-choice experiment), whereas in a comparative test they are simultaneously exposed to two or more stimuli. In both tests, preferences are measured by observing the frequency or latency of behavioural responses, such as positive taxis (e.g. the relative number of females that approach a stimulus in phonotaxis experiments, Gerhardt, 1995), the speed and direction on a walking compensator or of tethered movements (i.e phonotaxis in insects, Doherty, 1985),association time (i.e. the proportion of time spent in proximity to a visual stimulus in fish, Cummings and Mollaghan, 2006; Walling et al., 2010, and birds Hoi and Griggio, 2011; or to a chemical stimulus in mammals, CluttonBrock and McAuliffe, 2009), or the number of signals elicited (i.e. contact calls in birds, Moravec et al., 2006). Both recognition and comparative tests have several practical limitations, mainly due to the low accuracy and precision with which preferences are measured. While the low accuracy constrains the ability to describe variation in mating preferences and may limit our understanding of the selective forces acting on female mating decisions, the low precision of these tests is a somewhat more serious problem, because of the systematic errors it may introduce. Since there is no reasons to assume that choice probability in recognition tests is a linear function of preferences, these tests may describe the ranks, but not the quantitative differences in preference strength between items. Furthermore, dichotomous choice tests do not control for differences in female sampling tactics and, thus, they may confound repeated sampling of prospective mates as evidence for weak preferences (Bush et al., 2002).

In most cases, recognition and the comparative choice tests have been used to investigate how females respond to variation in single components of male signals. The interaction between mating preferences and male trait distribution determines the type of biological information received by females (Gerhardt, 1992): a monotonic function (or an unimodal function with peak either higher or lower than the mean) suggests that the trait is important for mate-quality assessment, whereas an unimodal preference function with peak close to the population mean is usually seen as evidence that the trait is important for species recognition because traits on both distribution tails are perceived as less attractive than those close to the mean. An unimodal preference function, however, may also arise as the effect of homotypic preferences, which make females more likely to mate with males of similar phenotypes, as it has been described in monogamous birds (Ludwig and Becker, 2008). In this case, the unimodal distribution of preferences reflects an unimodal distribution of phenotypes in the two sexes.

In many insects and anurans, females choose their mates on the basis of their advertisement calls (review in Gerhardt and Huber, 
2002). For example, Gerhardt (1991) shows that in grey treefrogs (Hyla chrysoscelis and $H$. versicolor) female preferences are stabilizing on some fine-scale temporal acoustic properties (pulse rate, call duration, rise time) and directional on some gross-scale temporal properties (call duration, call rate), suggesting that females acquire from the former information important for species recognition and from the latter information important for intra-specific discrimination (mate-quality assessment). This study has been replicated on many other anuran and insect species, confirming that one of the major advantages of acoustic communication is the potential for encoding multiple messages into a single signal (review in Gerhardt and Huber, 2002; Ryan, 2001).

Multiple messages in mating signals pose the question of how females process different sources of information. Since different cues or signals may provide females with conflicting information, it has become clear that the problem of assigning a preference value to prospective mates critically depends on how these cues interact with each other (Hebets and Papaj, 2005). From a theoretical point of view, females can integrate different sources of information into a one-dimension preference function by following two computational rules: an additive integration (Burke and Murphy, 2007; Kunzler and Bakker, 2001; Schul and Bush, 2002), when they make a weighted sum of the perceived attractiveness of each component, or a multiplicative interaction (Castellano, 2010; Castellano and Rosso, 2007; Schul and Bush, 2002), when components have a synergic effect on the overall perceived attractiveness. As observed by Schnupp and King (2001), when females weigh the components of a signal, they perform an operation analog to the logical "OR", because just a single highly attractive component may make the entire signal attractive. In contrast, when females multiply the perceived attractiveness of each component, they perform an operation analog to the logical "AND", because it suffices a single poorly attractive component to make the entire signal poorly attractive. Because of these computational differences, additive and multiplicative integration may solve different functional roles in mate choice. If components convey highly redundant information, then summation is expected to perform better than multiplication. In contrast, if they convey different sources of information, then multiplication is expected to do better. Castellano and Rosso (2007) and Castellano (2010) investigated female mating preferences for multiple-attribute signals in the Italian treefrog, Hyla intermedia. These studies supported the one-dimension preference-function hypothesis and provided evidence that acoustic properties important for species recognition and mate quality assessment interact multiplicatively with each other in determining overall signal attractiveness.

Brooks et al. (2005) described the shape of the preference function for multi-attribute mating signals in the cricket Teleogryllus commodus using multiple-regressions techniques. They tested female preferences on a set of 300 artificial calls, opportunely constructed to show simultaneous and uncorrelated variation in five acoustical traits. Then, they used non-linear regression models (with linear, quadratic and cross-product terms) to describe the female preference function over this set of calls and showed a dominant component of stabilizing multivariate preferences acting on the cricket call (Bentsen et al., 2006). A similar approach was used by Wagner and Basolo (2007) and by Gerhardt and Brooks (2009) to study multivariate preference functions on mating calls, respectively, in a cricket (Gryllus lineaticeps) and in a treefrog (Hyla versicolor). Wagner and Basolo (2007) considered only two acoustic traits that were known to convey different biological information and found that only one of them had statistically significant effects on the multivariate preference function. Gerhardt and Brooks (2009), in contrast, considered five acoustic traits and showed that the multivariate female preference function was significantly influenced by linear, quadratic, and cross-product terms.

\subsection{Variation in preference function}

Preference functions play a central role in the evolution of male secondary sexual traits (Andersson, 1994) and among-population variation in preference function may promote pre-zygotic isolation and, thus, speciation (review in Kirkpatrick and Ravigne, 2002). For these reasons, variation in preference functions has received great attention from evolutionary biologists (Brooks and Endler, 2001; Jennions and Petrie, 1997; Schielzeth et al., 2010; Widemo and Saether, 1999). Since our focus is on the processes of mate choice, we will not review this abundant literature, but we briefly consider the role of experience on preference functions. Widemo and Saether (1999) identified two components of preference functions: a fixed 'innate predisposition' to respond to certain stimuli and a 'flexible reference template'. Whether the former can be explained as the heritable components of neuro-sensory organs and might be immune to experience, the latter explains preferences that arise by comparing prospective mates against internal standards often acquired by experience. For example, in many birds (review by Riebel, 2003, 2009) and some spiders (Hebets, 2003), female preferences are influenced by early experience, whereas in several rodents they are affected by male familiarity: in some species familiar males are preferred over unfamiliar males (e.g. Harvest mice, Mycromys minutes, Brandt and Macdonald, 2011), in others species the opposite pattern is observed (e.g. mandarin voles, Microtus mandarinus, Tai et al., 2000).

In all these examples, experience causes variation in preference functions and, thus, in mating preferences. Variation in mating preferences, however, may arise also by a change in utility functions. In these cases, experience has no effect on the perceived attractiveness, but only on its perceived utility. As we shall see in the next section, utility functions are an important component of the decision variables, they may affect choosiness and, thus, they may play a central role in explaining short term plasticity in mating preferences (see Section 4.2).

\section{The decision variable}

The perceived attractiveness of prospective mates is one of the sources of information for mating decision. Our model assumes that females use the perceived attractiveness of males to infer their value (utility), which we express as the ratio between the two likelihoods $P(A \mid H)$ ) and $P\left(A \mid H^{c}\right)$. By combining this piece of information with what she already knows about a male (i.e. $P(H)$ ), a female can compute the posterior probability that the male is an appropriate mate. But, to estimate this quantity, should she rely only on her own perception of males' attractiveness (i.e. private information), or should she rely also on other sources of information, which she may acquire, for example, by observing how males interact with each other and with other females in the population (public information)? Recent studies have provided evidence for the role of the social context in influencing female mating decision. We review these studies in the light of our model of Bayesian mate choice.

\subsection{The role of public information and social eavesdropping in mating decisions: $P(H)$}

Social eavesdropping (McGregor, 2005) is the act of obtaining public information from signaling interactions between conspecifics (Valone, 1989; Valone and Templeton, 2002). It is thought to occur when an individual changes his behaviour towards a conspecific, after observing the latter in a social interaction (Bonnie and Earley, 2007). Social eavesdropping has been mainly studied in two behavioural contexts: agonistic territorial interactions (Magnhagen, 2006; Naguib and Todt, 1997) and mate choice (review in Dugatkin, 1996; Westneat et al., 2000; Witte, 2006). 
In mate choice, the use of public information has been observed mainly in fish and birds (review Galef, 2006; Valone, 2007; Westneat et al., 2000) and it appears to be more common in females than in males (but see Plath et al., 2009; Schlupp and Ryan, 1997; Widemo, 2006, for exceptions). Females can acquire public information on a prospective mate in two distinct ways. They may observe prospective mates in intra-sexual aggressive contests (Doutrelant and McGregor, 2000; Otter et al., 1999). For example, in female black-capped chickadees, Poecile atricapillus, the probability of extra-pair copulations depends on the outcome of male-male vocal contests. By experimentally manipulating the outcome of contests between the female's social partner and either an aggressive or submissive simulated opponent, Mennill et al. (2002, 2003) showed that females paired with high-ranking males were more likely to accept extra-pair sires when their partner had been exposed to aggressive rather than to submissive opponents. Interestingly, Ophir and Galef (2004) showed that, in Japanese quails, the use of public information depends on females' previous sexual experience: when observing an antagonistic interaction between two males, young virgin females preferred the most aggressive male, whereas the sexual experienced females preferred the least aggressive male. In this species, experience may alter the effect of public information, but not the aptitude for using it in mating decision.

A second mechanism to acquire social information on prospective mates is by observing them in inter-sexual courtship interactions. This mechanism of non-independent mate choice has been dubbed 'mate-copying', because it assumes that females, first, acquire information on prospective mates by observing sexual interactions between nearby males and females and, then, use this information to choose among those males (review in Dugatkin, 1996; Galef and White, 2000). Operatively, evidence for mate copying is given by showing that the probability that a 'focal' female chooses a certain male either increases or decreases depending on whether she has previously observed another ('model') female to choose or to reject that male (Witte and Ueding, 2003). Originally described in lekking birds and shoaling fish (review in Dugatkin, 1996; Witte, 2006), mate copying has been further observed in other vertebrate and invertebrate taxa (insects, Mery et al., 2009; mammals, Galef et al., 2008; humans, Little et al., 2008), suggesting that the role it plays in mating decision might depend more on the ecological constraints that limit the access to this source of public information rather than on cognitive constraints that prevent females to use it.

According to our model, public information influences the prior probability $(P(H))$, but it has no effects on either the attractiveness $(A)$ or the utility $(U(A))$ of prospective mates. A similar hypothesis was first presented in a verbal model by Nordell and Valone (1998) and, successively, formalized in a mathematical model of optimal Bayesian decision making by Uehara et al. (2005). According to this view, mate-choice copying and, more generally, the use of public information in mating decision does not represent an alternative, but rather a complementary strategy to the use of private information (Sirot, 2001). Two lines of empirical evidence support this view (Valone, 2007). First, the influence of public information on mating decisions increases with the decreasing quality of private information. Indeed, in a two-choice test, a female is more likely to adopt a mate-choice copying strategy when the males are similar to each other (Dugatkin, 1996; Dugatkin and Godin, 1992) than when they differ markedly (Brooks, 1996). Second, the role of public information decreases with increasing mating experience. In guppies, young females are more likely to copy older females than vice versa (Dugatkin and Godin, 1993) and when young females are allowed to observe both a young and an older model female, they are more likely to copy the latter than the former (Amlacher and Dugatkin, 2005). According to Valone (2007), old and experienced females rely more on their private information than younger females.

Although several studies show results consistent with the hypothesis that the effects of public information are on the male involved in the observed social interaction, there is also evidence for the alternative hypothesis that females can generalize the acquired public information to modify their mating preferences. White and Galef (2000) show that, in Japanese quails, females that have previously observed a conspecific male mating, may successively show a preference not only for that specific male, but also for males that share his characteristics. Similar results have been observed in zebra finches (Swaddle et al., 2005) and guppies (Godin et al., 2005) and also in an invertebrate, Drosophila melanogaster (Mery et al., 2009). According to this hypothesis female matechoice copying is a form of cultural transmission (Kirkpatrick and Dugatkin, 1994), because mate preferences evolve through mechanisms of social learning.

We have emphasized the role of public information on the priors of a Bayesian decision variable. However, females may construct priors also from previously acquired private information. For example, female satin bowerbirds, Ptilonorhynchus violaceus, are known to choose mates using mating experience of previous years (Uy et al., 2000) and, on a much shorter time scale, female field crickets, Teleogryllus oceanicus, are known to use information acquired by assessing long-range calls of a prospective mate when they evaluate the attractiveness of his short-range courtship songs (Rebar et al., 2009).

\subsection{The perceived utility of prospective mates: $U=P(A \mid H) / P\left(A \mid H^{c}\right)$}

To calculate the posterior probability $P(H \mid A)$, females must know how to use the male's perceived attractiveness to estimate the two conditional probabilities $P(A \mid H)$ and $P\left(A \mid H^{c}\right)$, the likelihood of perceiving a male at an attractiveness level $A$, respectively, when he is and when he is not an appropriate mate. Our model (see Eq. (4)) assumes that females have encoded in their genes and wired in their nervous system this simple rule: the ratio $P(A \mid H) / P\left(A \mid H^{c}\right)$ is a monotonic increasing function of the male perceived attractiveness. We called this relationship utility function (UF). In Fig. 2, we assume that the UF is linear, that is, we assume that the perceived value of a prospective mate depends on $A$ (the preference function, $\mathrm{PF})$ and on the two parameters that define the line: its slope and intercept.

If the slope and the intercept are fixed, then $A$ univocally determines $U$ and the decision variable, DV. In this case, PF and UF are virtually indistinguishable. In contrast, when females can adjust the UF parameters in relation to their experience, internal state, or external conditions, then the effect of the PF on the DV may change and PF and UF are to be distinguished. Suppose a female is evaluating two prospective mates (e.g. $M_{1}$ and $M_{2}$ in Fig. 2). An increase in the slope of the UF would increase the difference in the perceived values of the two males and, thus, it would increase the female's discrimination ability ( see also Bailey, 2008). In contrast, an increase in the intercept would increase the perceived values of the two males of a constant amount, causing an increase in permissiveness and a decrease in "choosiness" (Jennions and Petrie, 1997). Indeed, when the perceived values of males increase, females are more likely to accept them independent of their perceived attractiveness. Variation in "choosiness" has been usually seen as the effect of a change of the decision rule (e.g. variation in the searching tactic or in the acceptance threshold). Our model suggests that this variation may arise also by a change in the DV.

Plasticity in mating decisions is a widespread and well studied phenomenon (review in Jennions and Petrie, 1997; Widemo and Saether, 1999). Mate choice occurs only during the breeding season. Thus, mating decisions depend on female reproductive 
A

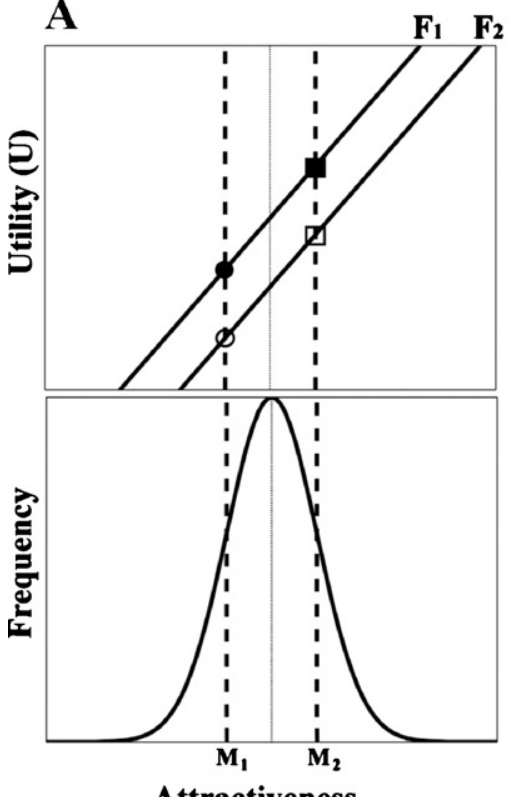

B

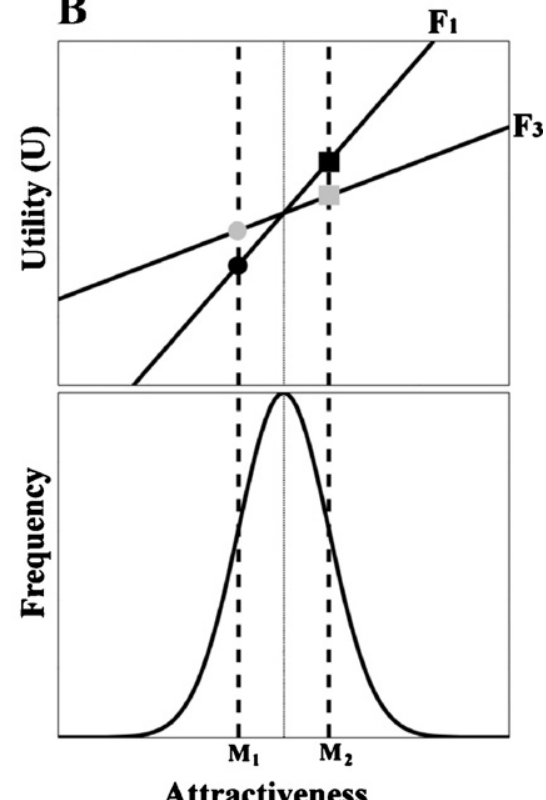

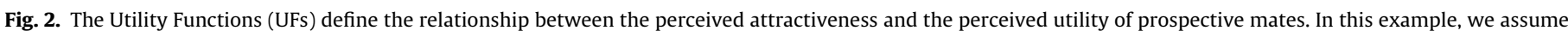

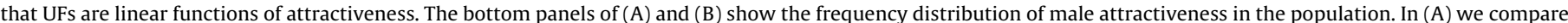

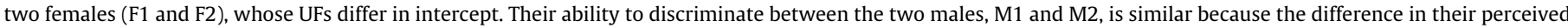

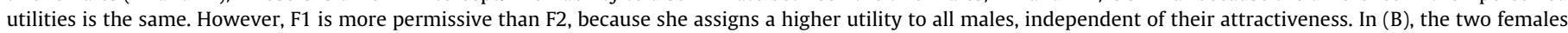

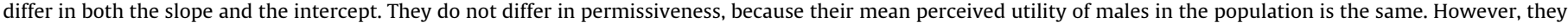
do differ in the ability to discriminate between mates. In fact, the difference in the perceived utility of M1 and M2 is larger in F1 than in F3.

stage (Forsgren, 1997; Gabor and Halliday, 1997; Lynch et al., 2005; Qvarnstrom et al., 2000). For example, a study on plasticity in mating preference in Túngara frog females (Lynch et al., 2005) has shown that the probability of recognizing both a conspecific call (receptivity) and a call less attractive than a conspecific call (permissiveness) changes during the reproductive stages of females, probably because of differences in their hormonal state (Lynch et al., 2006). Receptivity and permissiveness are higher in the amplexed than in the pre- and post-amplexed stages, but the probability of discriminating between two conspecific calls of different attractiveness does not change. These results suggest that hormones affect the intercept, but probably not the slope of the UF.

Plasticity in mating decisions has been found to be related not only to female reproductive stage, but also to female condition (Burley and Foster, 2006; Eraly et al., 2009; Fisher and Rosenthal, 2006; Fawcett and Johnstone, 2003a; Moskalik and Uetz, 2011; Poulin, 1994; Slagsvold et al., 1988), to age (Bateman et al., 2001; Kodric-Brown and Nicoletto, 2001; Moore and Moore, 2001), and to ecological (Booksmythe et al., 2008; Chaine and Lyon, 2008; Forsgren, 1992; Godin and Briggs, 1996; Gong and Gibson, 1996; Milner et al., 2010) and social conditions (Bailey and Zuk, 2008, 2009; Collins, 1995; Hebets, 2003; Izzo and Gray, 2011; Lehmann, 2007; Rebar et al., 2011; Wagner et al., 2001). In particular, strong evidence for an effect of social experience on mating preferences has been provided by studies on the cricket Teleogryllus oceanicus. In this species, pre-copulatory mate choice is influenced by experience of male calling song: females are less responsive if they have been previously exposed to male calling (Bailey and Zuk, 2008, 2009). Furthermore, females that have experienced a poorly attractive male are subsequently more likely to choose a male and to retain his spermatophore for longer than females that have experienced a highly attractive male (Rebar et al., 2011). This pattern might be explained by assuming that females adjust the intercept of the UF to the local distribution of male attractiveness (see Fig. 3), increasing choosiness as the perceived mean attractiveness level increases.

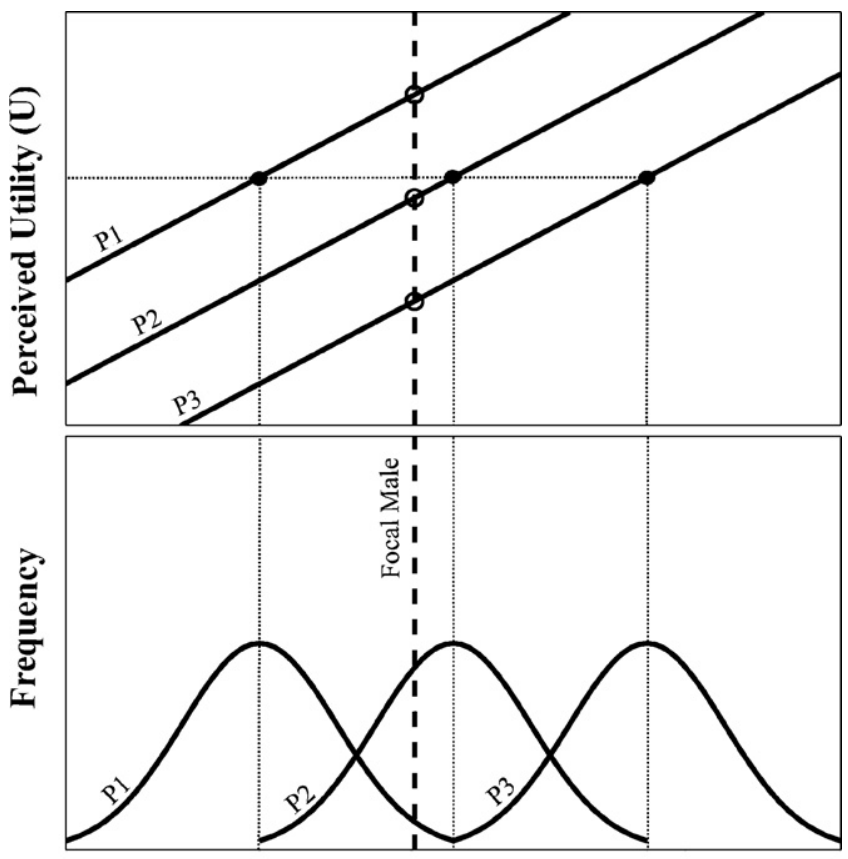

Perceived Attractiveness (A)

Fig. 3. The plastic Utility-Function hypothesis. We present an hypothesis of how a female could adjust her decision variable to the local distribution of perceived male attractiveness, by changing the intercept of her utility function. The three lines in the top panel represent the utility functions (UF) of the same female when she has been exposed to three different distributions of male attractiveness (P1, P2, and P3 - bottom panel). The model assumes that the female adjusts her UF so that the same utility score is associated to the perceived mean attractiveness of males. As a consequence, the perceived utility of a focal male is not constant, but it depends on the female's previous experience. 
As mentioned above, however, variation in female choosiness may be due to a variation in the decision rule (DR) rather than in the decision variable (DV). Indeed, this pattern has been usually explained as evidence for a flexible threshold in decision rules (Wagner et al., 2001). Since the two hypotheses are not necessarily alternative to each other, it may not be easy to devise an empirical experiment able to contrast them. In the next section, we deal with decision rules.

\section{The decision rules}

Whether a DV is continuous, choice is a discrete categorical variable (females must choose either one of the alternatives). The decision rule (DR) is the function that converts the continuous DV into the discrete choice (Gold and Shadlen, 2007). Two types of DRs can be identified: the absolute and the comparative DRs. An absolute DR is obtained by setting a threshold, when a DV is above the threshold then the decision maker commits to the hypothesis associated with that DV. In contrast, a comparative DR, typically, examines several alternative hypotheses and commits to the one supported by the most robust evidence. For example, in statistics, a traditional null-hypothesis test adopts an absolute decision rule. In this case, the statistics represents the DVs and the critical value of the statistics associated to the desired Type I error represents the threshold. In contrast, the model selection approach in statistics might be viewed as an example of comparative decision rule.

\subsection{Theoretical background}

Although mate choice arises by applying a decision rule to a pattern of preferences, these two components of mate choice have been rarely analysed within a unitary theoretical framework (Gibson and Langen, 1996). Typically, studies that focus on mating preferences (i.e. on the decision variable) aim at understanding the relationship between signal variation and mating success, and adopt a 'descriptive' approach. In contrast, studies that focus on mating decision rules aim at understanding how females gather and use information on prospective mates for optimal mating decision and, thus, they adopt a 'normative' approach (Castellano and Cermelli, 2011).

Since the pioneering theoretical studies of Janetos (1980) and Parker $(1978,1983)$, normative models of mate choice have been developed in an optimality rather than in a game theoretic framework, in that they assume there is a single choosy sex, whose behaviour does not affect the advertising strategy of the other sex (but see Fawcett and Johnstone, 2003a; Gualla et al., 2008; Johnstone, 1996). These models try to explain mating decision rules on the basis of how information is collected, that is, on the basis of how females sample prospective mates. These models have identified three main sampling tactics: (i) random choice; (ii) sequential searching (SS models) and (iii) fixed-sample-search tactics (FS models, also known as best-of-n models).

The random choice model assumes simply that females mate with the first conspecific male they encounter and, thus, it represents a sort of 'null-model' against which to compare the others. In SS models, females are assumed to use an absolute DR, in that they do not keep memory of previously assessed males and sample prospective mates until they find a male with quality equal to or greater than a certain threshold. In the FS models, females are assumed to use a comparative rule, they sample a fix number of prospective mates, keep memory of them, and choose the best among them (Real, 1990). An interesting variant of the FS model has been proposed by Luttbeg (1996) and named the "comparative Bayesian" model (CB). Like in the FS model, females are assumed to choose the best among a sample of males, but the sample size is not fixed and females are allowed to improve mate evaluation by repeatedly assessing prospective mates according to a Bayesian updating procedure (see below).

Under the adaptationist assumption that natural selection has favoured the evolution of optimal mate sampling tactics, theoreticians have compared the performance of these normative models of mate choice to find out which is expected to fare better. Optimal decision rules, however, largely depends on the assumptions on which these models are based.

A first critical assumption is about searching costs. Janetos (1980) assigns no costs on mate searching and, thus, concludes that FS models perform better than SS models. Real (1990) shows, however, that if costs are introduced in the model, the FS decision rule is outperformed by a SS model in which females adopt a fixthreshold decision rule (Wiegmann et al., 2010b). This rule, in fact, allows females that encounter a high-quality male at the beginning of their search to avoid the costs of further search.

A second critical assumption is about the role of uncertainty in the decision process. Two types of uncertainty may be identified: uncertainty about the distribution of mate quality in the population and uncertainty about the quality of a prospective mate. The uncertainty on the local quality distribution has a relevant effect on mate-search tactics. Real's (1990) model assumes females to know the local distribution of male qualities, which is uniform or truncated normal. However, when the distribution of male quality is allowed to vary both spatially and temporally, the SS model with fixed-threshold is no longer the optimal mate sampling tactic (Mazalov et al., 1996; Luttbeg, 2002) and it is outperformed by adaptive SS models, in which females learn from previous experience and update their acceptance threshold accordingly (Collins et al., 2006; Dombrovsky and Perrin, 1994; Mazalov et al., 1996). Collins et al. (2006) present a Bayesian model for updating information in a social environment where the mate-quality distribution is expected to vary in both the mean and the dispersion around the mean. In this model, females assess male quality without error. Under these conditions, the optimal rule is learning: females choose their mates on the basis of an acceptance threshold defined by the sum between the current estimate of the population mean and an additive component that decreases with the increasing number of sampled males.

The effect of the second type of uncertainty (uncertainty in mate-quality assessment) has been investigated by Wiegmann and Angeloni (2007). In their model, females are assumed to be able to assess only a subset of a male's fitness-related attributes so that the expected benefits for a female are no longer deterministic, but stochastic. They find that stochasticity does not affect the qualitative behaviour of both the FS and the SS models. Given that the expected benefits of choice continue to increase monotonically with the observed male attributes, the SS model always fare better than the FS model (see also Wiegmann et al., 2010a).

In Wiegmann and Angeloni (2007), females are assumed to have no control over the level of uncertainty in their evaluation. In contrast, the comparative Bayesian model of mate choice (Luttbeg, 1996), gives females control over their assessment accuracy. In Luttbeg's model, females have an uncertain prior estimate of the quality of each prospective mate, and, at any step of the decision process, they could decide either to use this information (and choose) or to continue the evaluation by improving assessment accuracy. Females stop evaluating males and choose the best alternative when the cost of more information exceeds the expected benefits of that information (Luttbeg, 1996).

Other two assumptions that affect the relative performance of mate decision rules are the constraints on both the number of available alternatives and the maximum spendable time for making decision. All models presented so far assume an infinite number of alternatives from which to choose and an infinite time horizon. 
Luttbeg (2002) used simulations to investigate the effects of these assumptions on FS, SS and CB models of choice. Simulations showed that a reduction in both the number of options and the time for choosing had stronger effects on the performance of SS model (with fix threshold) than on that of both the FS and CB models. He concluded that, in natural conditions, comparative decision rules could be as effective as, or even more effective than absolute decision rules.

\subsection{The empirical evidence for decision rules}

Theoretical studies of mate choice have strongly influenced the empirical research. Based on the adaptationist assumption that selection would provide decision makers with optimal decision rules, researchers have used simulations to compare the performance of different models and to predict which of them was most likely to occur in natural conditions (Janetos, 1980; Luttbeg, 2002; Real, 1990). As we have shown above, however, the relative performance of decision models strongly depends on their assumptions (Luttbeg, 2002; Luttbeg and Langen, 2004). It seems, thus, unlikely that the optimality approach on theoretical models could provide direct evidence for optimal mate searching tactics in natural conditions.

Nevertheless, theoretical models could play an invaluable role in understanding mate choice in natural conditions, for two reasons. First, empiricists deal with patterns and, without models, it would be impossible to explain them in terms of their underlying mechanisms. Second, empiricists want to understand why such mechanisms evolved and models could show which factors are more likely to have favoured or constrained the evolution of these mechanisms.

\subsubsection{Random choice}

Many field studies have shown patterns apparently consistent with the random choice model. In lekking anurans, females usually sample males simultaneously from a distance and several field studies have shown female preferences for the closest male (Arak, 1988; Friedl and Klump, 2005; Grafe, 1997), a pattern which has been suggested to arise as the effect of "passive attraction" to the perceived loudest call (Arak, 1988; Parker, 1982; but see Castellano et al., 2004; Murphy, 2008). Friedl and Klump (2005) observed that in lekking anurans, the mating success of males depended more on their lek attendance than on their courtship performance and concluded that female choice was random and played a marginal role in determining male mating success. According to Friedl and Klump (2005), a female that mates randomly saves the costs of searching and, at the same time, is still likely to mate with a high-quality male, because high-quality males could spend more time in advertising and thus are more likely to be randomly selected by females.

In general, however, it is hard to see how random female choice could have promoted the evolution of a courtship behaviour as costly as the calling of chorusing anurans (Castellano, 2009b). What we perceive as evidence of random female choice (i.e. the lack of a correlation between mating success and courtship behvaiour of males) may be the effect of a strong female preference for highadvertising levels, which forces males either to attain to those levels or to abandon the competition (Castellano, 2009b; Johnstone, 1994). For this reason, we suggest caution from taking randomchoice patterns as evidence for permissive mating decisions, in particular, when the costs of mate searching are presumably low (such as in leks).

\subsubsection{Fixed sample}

Evidence for comparison decision rules (FS model) in mate choice comes mainly from lekking species (review in Jennions and Petrie, 1997), in which the costs of searching are generally low and females may assess several mates simultaneously. In many chorusing treefrogs, for example, females do not move among calling males, but reach a location, from where they assess several males simultaneously (Murphy and Gerhardt, 2002). Field experiments on gray treefrogs have shown that the time required to reach a decision may be rather short (about $2 \mathrm{~min}$ ) (Schwartz et al., 2004). It is not clear whether this short assessment time is due to cognitive constraints on working memory (Akre and Ryan, 2010) or whether it represents an optimal tradeoff between the costs and the benefits of male assessment. A mate-sampling pattern consistent with a FS decision model has been observed also in non-lekking species of birds (Hovi and Ratti, 1994) and mammals (Byers et al., 2005; Ferretti et al., 2011). For example, Dale et al. (1992) provided evidence that female pied flycatchers adopted a comparison decision rule: females visited several males (three, on average) before committing, often returned to a previously assessed male, and the probability of choosing a male did not depend on his position in the sampling sequence of prospective mates (Dale and Slagsvold, 1996). On average, females spent about $5 \mathrm{~h}$ searching for mates, and in one hour they were able to visit up to seven different prospective mates. In the Satin bowerbird (Ptilonorchynchus violaceous), females were found to search for mates for very long periods (15 days, Uy et al., 2000). Before choosing their mate, females visited several males for courtship and then they returned to a subsample of them for further evaluation. Females were found to remember the assessed males not only within, but also between breeding seasons. Since males of this species use the same bower site in successive years (Borgia, 1993), there is evidence that females use previous mating experience in mating decisions: females who, in the previous year, mated with highly attractive mates, in the successive year visited a smaller number of males and were more likely to re-mate with the same male than were females previously mated with unattractive males (Uy et al., 2000).

\subsubsection{Sequential search}

In SS models, females compare males against an internal standard, which may be either fixed or variable. The distinction between the fixed and variable threshold models is ambiguous because, as we have pointed out above, it is not clear whether experience affects the decision rule (i.e. the threshold) or the decision variable (as assumed by our Bayesian model) or both. The SS models do not require females to keep memory of individual males (but only of their distribution) and thus these tactics are thought to impose less severe cognitive constraints on female performance than those imposed by the FS model (and comparative DR).

In practice, both field studies and choice experiments have been difficult to provide clear evidence for SS decision rules (Jennions and Petrie, 1997; Valone et al., 1996; Widemo and Saether, 1999). The SS model assumes no recall of previously sampled males and thus predicts that choice is for the last of a sequence of sampled prospective mates. However, this rule may result in a pattern consistent with the FS rule if males, by chance, can be sampled more than once, and if females accept males that were previously rejected because of either a variation in flexible thresholds or, simply, an evaluation error in case of fixed thresholds (Luttbeg, 2002; Luttbeg and Langen, 2004). Strong evidence for SS decision rule was reported by Gibson (1996) in the sage grouse, Centrocercus urophasianus, and by Reid and Stamps (1997) in the pine engraver, Ips pini. In the latter study, the observed pattern was consistent with the SS model with a flexible threshold: females often mated with the first male encountered, rarely returned to a visited male, and adjusted their acceptance threshold in relation to the quality of the patches.

As it concerns the experimental approach, two lines of evidence have been proposed to support the hypothesis of SS decision rules. First, in two choice discrimination tests, the presence of 
an acceptance threshold is shown if females fail to discriminate between two low-quality alternatives. Zuk et al. (1990) showed that red jungle fowl females (Gallus gallus), when given a choice between two males with large combs, preferred the one with the largest attribute, but when both prospective mates had small combs, females did not choose or chose randomly. It should be noticed that, even if an acceptance threshold does exist in this species, it does not prevent females from choosing the best of the two alternatives when both were above the acceptance threshold. A second line of evidence comes from studies that compare patterns of mating preferences obtained under different experimental conditions. Moore \& Moore (1988) studied female mating decision in a cockroach (Nauphoeta cinerea) and found that mating behaviour was unaffected by the number of available alternatives: the latency to approach, to respond to or to mate with a male did not depend on whether females were tested in two-choice test (between dominant and subordinate males) or in no-choice test (either dominant or subordinate male). They concluded that female cockroaches did not compare alternatives against each other, but against an internal, fixed standard.

Another study supporting the SS model is that by Beckers and Wagner (2011) on mate sampling strategies in Gryllus lineaticeps. Females were tested in three-stimulus choice experiments. They showed preferences for chirp rates higher than 3 chirps/s over alternatives with chirp rates lower than 3 chirps/s, but failed to show any preference among calls with chirp rates all higher or all lower than 3 chirps/s. Interestingly, previous experiments using a twochoice testing paradigm provided evidence for much finer levels of discrimination among chirp rates (Wagner and Basolo, 2007), thus suggesting that decision rules may depend on the number of stimuli to which females are simultaneously exposed.

\subsection{Does variation in the pattern of choice reflect variation in decision rules?}

Despite the strong theoretical and empirical effort, the question of how females choose their mates remains largely unresolved. Jennions and Petrie (1997) suggested that this may be due to variation in mate-decision rules. Variation may occur at the withinpopulation level. For example, most female pied flycatchers visit several males before mating (Dale et al., 1992; Dale and Slagsvold, 1996; Hovi and Ratti, 1994), but others mate with the first or with the last encountered male, showing patterns consistent with both the FS and the SS models (Fiske and Kalas, 1995). But variation may also occur at the within-individual level. As reported above, Beckers and Wagner (2011) showed that G. lineaticeps females used a threshold rule when choosing among three alternatives, but switched to a comparative rule when choosing between two alternatives. MacLaren and Rowland (2006) compared female preferences for male body size in sailfin mollies, Poecilia latipinna. They observed a much stronger preference for large size when alternatives were presented in a paired fashion rather than sequentially, suggesting that females applied comparative decision rules only when simultaneous evaluation was possible. Brandt et al. (2005) showed that lesser wax moth females, Achroia grisella, used both absolute and relative criteria to choose their mates: independent of the number of available prospective mates, they rejected mates that call at a rate lower than a fixed threshold, but, when several males called above the acceptance threshold, females chose the one with the highest rate.

These empirical studies pose an important theoretical question: Is variation in the pattern of choice the effect of different decision rules, or is it the effect of different contexts in which the same decision rule is used? We argue that to respond to this question, we should adopt a computational approach that aims at explaining decision rules in terms of their underlying information-processing mechanisms (Castellano, 2009a).

Castellano and Cermelli (2006) and Phelps et al. (2006) presented two models to study the relationship between recognition and discrimination in mating decision. In Castellano and Cermelli's (2006) model, the probability of choosing a mate A over an alternative $B$, was assumed to be the sum of the probability that only $A$ was recognized as an appropriate mate and the combined probability that both $A$ and $B$ were recognized, but $A$ was preferred to B. Phelps et al. (2006) used signal detection theory to link perception to decision. In their model, the perceived attractiveness of a prospective mate was a stochastic normal variable with variance proportional to the level of uncertainty (see Eq. (1)). Females were assumed to choose the most attractive male that exceeded a minimal recognition threshold (Phelps et al., 2006). In these models, the mating-decision mechanism depends on both absolute (the recognition threshold) and comparative DRs and it could be used independent of females' mate-sampling tactics.

According to these models, recognition and discrimination are the expression of the same cognitive machinery, which uses the same "currency" for making decision (the preference strength in Phelps et al. (2006), the amount of evidence, $A$, in our model - see Eq. (1)). Another possibility, however, is that recognition and discrimination are different processes that evolved to solve different tasks. In this case, we should expect a task-specific role of signal attributes in relation to the type of information they convey. In recognition tests, signal attributes that convey information important for species recognition should affect female mating decision more strongly than attributes important for mate discrimination. In discrimination tests, the opposite pattern should be observed. Phelps et al. (2006) measured female preference strength over a set of signals in both recognition and discrimination experiments and found a strong correspondence between the two preference scales. Bush et al. (2002) used recognition tests, but measured female preferences as the ratio between the time required to respond to a certain stimulus and to a standard signal (the latency-ratio test). They found broad similarities between the preference functions obtained with the latency-ratio test and the two-choice discrimination tests. Overall, these studies provide empirical evidence that recognition and discrimination are the expression of the same cognitive machinery (Castellano, 2009a).

\section{Sequential sampling models of mate choice}

In Phelps et al.'s model (2006), the strength of preference between the two alternatives depends on the level of uncertainty (accuracy) of male assessment, but females have no control over it. As in most of signal detection models, in Phelps et al.'s (2006) model, uncertainty may be viewed as the random sampling error that arises from the integration of independent pieces of evidence over a fixed evaluation time (Castellano, 2009a; Pleskac and Busemeyer, 2010). In fact, suppose that (i) a female, during a fixed time interval $T$, uses $n$ pieces of evidence to assess the attractiveness of a mate, (ii) each piece of evidence can be either a positive $(+1=$ the male is an appropriate mate $)$ or a null evaluation $(0=$ no evidence that the male is an appropriate mate), and (iii) $p$ is the probability of a positive evaluation. If $n$ is sufficiently large, then the amount of evidence approximates a normal distribution with mean $n p$ and variance $n p(1-p)$.

Recently, Castellano and Cermelli (2011) presented a sequential-sampling model of mate choice that can be viewed as a logical extension of the signal detection model of Phelps et al. (2006). Sequential-sampling models of decision making are a dynamic variant of signal detection models (Pleskac and Busemeyer, 2010), in that they drop the assumption that decision makers use a fixed sample size of evidence and assume that 
decision is made as soon as the accumulating noisy evidence reaches a fixed threshold (Castellano, 2009a; Castellano and Cermelli, 2011).

Unlike signal detection models, sequential-sampling models incorporate time in the decision process and, thus, they could be used for investigating speed-accuracy tradeoffs in decision making (Chittka et al., 2009; Sullivan, 1994) and for making testable predictions on the relationship between choice probability and time response (Kacelnik et al., 2011; Shapiro et al., 2008). Although these models have been only recently introduced in behavioural ecology (Castellano and Cermelli, 2011; Kacelnik et al., 2011; Shapiro et al., 2008; Trimmer et al., 2008), they have a long history in cognitive psychology (review in Ratcliff and Smith, 2004) and in neurobiology (review in Bogacz, 2007; Gold and Shadlen, 2007; Smith and Ratcliff, 2004) and they could represent a useful theoretical tool for building bridges between neurobiology and behaviour (Busemeyer et al., 2006).

Sequential sampling models have been developed to account for simple two-choice decisions, although they have been also used for modeling multi-alternative decisions (Roe et al., 2001). Two types of sequential sampling models have been proposed: race (or accumulator) and random-walk (or diffusion) models. In race models, evidence in favour of one alternative is accumulated in one response counter and evidence in favour of the other alternative is accumulated on another counter. Decision is made when one of the two counters reaches a fixed criterion amount of evidence. This stopping rule is defined as 'absolute' because counters accumulate evidence over time independently, without interaction. In the second type of sequential sampling models (random-walk models sensu stricto), evidence for either the alternatives accumulate as a single total, which is the difference in the amount of evidence between the alternatives (for this reason, Kacelnik et al. (2011) proposed for them the picturesque name of 'tug-of-war' models). Random-walk models assume that evidence accumulates at discrete time intervals. When evidence accumulates continuously with time, sequential sampling models are named diffusion models (Ratcliff and Smith, 2004).

Castellano and Cermelli's (2011) model of mate choice is an example of accumulator model in that it assumes females to associate to each prospective mate a "counter". Although females may evaluate several males simultaneously, assessment is assumed to be a serial rather than a parallel processing task: females, in fact, are thought to conduct a repeated sequential scanning of prospective mates and to acquire information on one male at a time. In this way, the model makes the plausible assumption that the rate of information gathering depends more on female intrinsic cognitive constraints than on extrinsic ecological factors (such as the number of males that could be evaluated simultaneously).

Two issues were investigated using this model (Castellano and Cermelli, 2011). The first was optimality in mating decision. Optimal choice was described in terms of the trade-off between the acceptance threshold and the number of males simultaneously assessed. Results of simulations showed that, unless costs were very close to zero, the optimal strategy was always assessing several males using a cost-dependent acceptance threshold. The second issue was the description of female mating preferences under three experimental choice paradigms: recognition (no-choice), discrimination (two-choice), and time latency tests. The model showed that recognition and discrimination tests provided an inaccurate description of mating preferences, because they introduced systematic errors that either attenuated (recognition tests) or exaggerated (discrimination test) the true differences in mating preference. In contrast, the latency-ratio test (Bush et al., 2002) performed much better than the recognition and discrimination tests, emphasizing the importance of time responses in assessing female mating preferences (Bush et al., 2002; Leonard and Hedrick, 2010; Rebar et al., 2011; Shackleton et al., 2005), as already shown in other contexts of choice (i.e. food preferences Bateson and Kacelnik, 1995; Reboreda and Kacelnik, 1991).

The sequential sampling models may become an appropriate theoretical framework to understand mate choice from the joint perspective of the ultimate (functional) and proximate (mechanistic) causes (Castellano, 2009a). Castellano and Cermelli's (2011) model, as well as all the accumulator models, assumes that evidence for each alternative accumulates separately without interaction. From this assumption it derives the prediction that, in two-choice discrimination tests, the more similar the attractiveness of the two stimuli, the shorter the latency to choose. In contrast, if the model assumes a direct comparison between the two alternatives, so that there exists only one decision variable (either the difference or the ratio between the strength of evidence supporting one over the other alternative), then the (random-walk) model predicts that the more similar the attractiveness of the two stimuli the longer the latency to choose. In humans, we usually find support for the comparative model: response time increases and accuracy decreases with increasing difficulty of the discrimination task (Luce, 1986). In contrast, very little is known on how other animals use information in simultaneous choice.

So far, behavioural ecologists have tackled this question in a context different from mate choice: prey selection (Kacelnik et al., 2011; Shapiro et al., 2008; Vasconcelos et al., 2010). Kacelnik and colleagues tested the two sequential sampling models of making decision (with and without comparison between alternatives) using the European Starling, Sturnus vulgaris, in laboratory tests on prey selection. By measuring latency to choose, they provided evidence that starlings, in simultaneous encounters, did not adopt a comparative evaluation, but processed each alternative independently. Since, in natural conditions, starlings rarely incur in two food items simultaneously, they suggested that natural selection had not favoured the evolution of cognitive mechanisms to efficiently compare and select the best of the two alternatives.

As it concerns mate choice, we may expect natural selection to have favoured the evolution of comparative mechanisms of choice in species where simultaneous encounters of prospective mates are common, as it is in lekking species. Although no studies have yet tested this hypothesis, episodic evidence seems to support it. In Tungara frogs, for example, Phelps et al. (2006) and Bosch et al. (2000) found a negative correlation between the difficulty of discrimination and the latency to choose, as predicted by the comparative sequential sampling models of choice.

\subsection{A Bayesian sequential-sampling model of choice}

In all sequential-sampling models described so far, the DV is a scalar quantity and the evaluation process (the integration of evidence over time) is equivalent to the computation of the arithmetic mean. In our model, however, the DV is the posterior probability of a Bayesian computation and integration over time can no longer be modeled as an additive, linear process. Bayes' rule yields an alternative framework to study the process by which males are evaluated iteratively (Deneve, 2009). Assuming that evaluation takes place at discrete time steps $t_{i}$, the resulting accumulation of evidence can be described by an update of the prior estimate of the male according to the actual estimate of the male attractiveness, i.e., $P\left(H, t_{i}\right)=P\left(H \mid A, t_{i}\right)$. By Bayes' rule, we may incorporate this assumption in the recursive relation

$P\left(H \mid A, t_{i+1}\right)=\frac{u(A)}{(u(A)-1)+\frac{1}{P\left(A \mid H, t_{i}\right)}}$ 
Again, it is the utility of the preference value that determines the outcome of the evaluation process, if $u(A)<1$, then $P\left(H \mid A, t_{i}\right) \rightarrow 0$ as $t_{i}$ increases: male is almost surely rejected if $u(A)>1$, then $P\left(H \mid A, t_{i}\right) \rightarrow 1$ as $t_{i}$ increases: male is almost surely accepted, irrespective of the initial prior estimate of the male $P\left(H \mid A, t_{0}\right)=P\left(H, t_{0}\right)$.

This procedure permits to integrate new pieces of information with what is currently known, to reduce uncertainty of the perceived world. In control theory, a very similar procedure takes the name of 'Kalman' filtering (Körding, 2007). At each instant, a Kalman filter combines acquired information about a system (i.e. the prior) with a measured observation (the likelihood) to update predictions of the current state of the system (the posterior probability). Kalman filters have found several applications, for example, in aeronautics and in humanoid robotics (see references in Berniker and Körding, 2011) and they have been used also in neuroscience, to develop neuro-physiological models of motor controls (Berniker and Körding, 2011).

\section{Multiple cues, multi-dimension preference functions, and multiple decision variables}

So far, we have assumed that females use a one-dimension representation of male attractiveness. However, when females assess several cues and signals across multiple sensory modalities, the internal representation of male attractiveness may be multidimensional, involving multiple preference functions (Fawcett and Johnstone, 2003b; Hohenlohe and Arnold, 2010). In these cases (see also Section 3), there may be a single DV that integrates information from multiple preference functions or there may be as many DVs as the number of preference functions. In the latter case, mating decisions depend on the priority that females assign to each DV.

The first case is an example of Bayesian integration of multiple sensory cues, in which the DV is the conditional probability of a male to be perceived as an appropriate mate, given his multidimension attractiveness. In a two dimension representation of mate attractiveness, for example, Eq. (2) becomes:

$P\left(H \mid A_{1}, A_{2}\right)=\frac{P\left(A_{1}, A_{2} \mid H\right)}{P\left(A_{1}, A_{2}\right)} P(H)$

If $A_{1}$ and $A_{2}$ involve traits from different sensory modalities so that their noise sources are statistically independent (Knill and Pouget, 2004), then Eq. (5) can be rewritten as:

$P\left(H \mid A_{1}, A_{2}\right)=\frac{P\left(A_{1} \mid H\right) P\left(A_{2} \mid H\right)}{P\left(A_{1}\right) P\left(A_{2}\right)} P(H)$

Eq. (6) predicts that when the relative uncertainty of each cue differs, the integrated estimate is biased toward the more reliable cue (Knill and Pouget, 2004), in other words, it predicts females to weigh cues in relation to their level of uncertainty. This prediction is consistent with the observation that female mating decisions are often flexible and biased to the cues with the largest differences between prospective mates. For example, female pied flycatchers, when given a choice between two males that differed in plumage colour and quality of the defended nest, choose on the basis of the cue that differed more heavily between males (Dale and Slagsvold, 1996). In the three-spined stickleback Gasterosteus aculeatus, females change their mating decision in relation to the environmental conditions: in clear water, they rely more on visual than olfactory cues, but the pattern is reversed in turbid water (Heuschele et al., 2009). Similar patterns of flexible preferences for multi-component signals were also observed by Calkins and Burley (2003) in the Californian Quail, Callipepla californica, and in the wolf spider Schizocosa ocreata (Scheffer et al., 1996).

A second possibility for processing multi-dimension preference functions is to associate to each preference function a decision variable and to order decision variables in terms of importance.
In human decision making this decision process is named "takethe-best rule" and is an example of "fast" and "frugal" heuristics (see Hutchinson and Gigerenzer, 2005). Prospective mates are compared with respect to the most important attribute. If one of them is preferred over the alternatives then that male is chosen regardless of the perceived values of the other attributes. If no male is preferred, then the second attribute in order of importance is considered, then the third, and so on. Empirical evidence for hierarchical assessment of multi-attribute signals is scarce. Scheuber et al. (2004) studied female preferences for multi-attribute acoustic signals in the field cricket, Gryllus campestris. In univariate two choice tests, female crickets preferred higher-than-average chirp rates and lower-than-average chirp frequencies, but when females were given a choice between a call with low frequency and low chirp rate and an alternative with high frequency and high chirp rate the preference for the low-frequency call was apparently unaffected by the low chirp rate, suggesting a hierarchical evaluation of the two acoustic properties. A similar pattern of preferences was also observed in guppies: females were found to prefer males with large rather than small orange areas and with bright rather than dull coloration, but when the two attributes were negatively correlated, female choice depended on the size of the orange spots, but not on the intensity of their coloration (Karino et al., 2010).

Hierarchical assessment of multiple cues has been proposed as a simple but effective decisional mechanism that does not require large amount of information and allows fast and effective decisions, even under strong cognitive limitations (Gigerenzer and Todd, 1999). As observed for animals, the empirical evidence that humans use this heuristics are however scant (Newell, 2005) and alternative and more parsimonious decision-making models have been suggested. In particular, Lee and Cummins (2004) presented a Bayesian sequential-sampling model of choice, in which decision makers were assumed to accumulate evidence in favour of either one of the two alternatives by sequentially sampling their attributes until an acceptance threshold was reached. For low thresholds, the model predicted patterns of choice similar to those obtained from hierarchical-assessment models (Lee and Cummins, 2004). According to these authors, the "take-the-best" heuristics (i.e. hierarchical assessment) is not an alternative mechanism, but a special case of a more general model of decision making (Newell, 2005).

\section{Comparative mate choice and rationality in decision making}

If females order males along a one-dimension preference function and choose the male with the highest preference score, then mate choice is expected to obey to three principles of economic rationality: transitivity, regularity and independence of irrelevant alternatives (IIA) (Kacelnik, 2006; Houston et al., 2007a,b; Roe et al., 2001).

Transitivity is a condition related to the pattern of dichotomous preferences over a set of three or more alternatives. It requires that, given three options $\mathrm{A}, \mathrm{B}$, and $\mathrm{C}$, if a female prefers $\mathrm{A}$ over $\mathrm{B}$ and $\mathrm{B}$ over $\mathrm{C}$, then she must prefer also $\mathrm{A}$ over $\mathrm{C}$. The conditions of regularity and the IIA require that the relative preference for $A$ over $B$ does not change when a third alternative is added to the choice set, because this new option is expected to take from the others proportionally to their original shares (Heath and Chatterjee, 1995). In marketing research, however, both the regularity and the IIA conditions are known to be consistently violated when an asymmetrically decoy is added to the set of two or more items. In Fig. 4, we show two examples of violation, known as the "similarity effect" and the "attraction effect". The "similarity effect" is observed when an asymmetrically competitive decoy $(C)$ is added to a set of dissimilar and equally preferred items ( $\mathrm{A}$ and $\mathrm{B}$ ). The $\mathrm{C}$ item is an asymmetrically competitive 

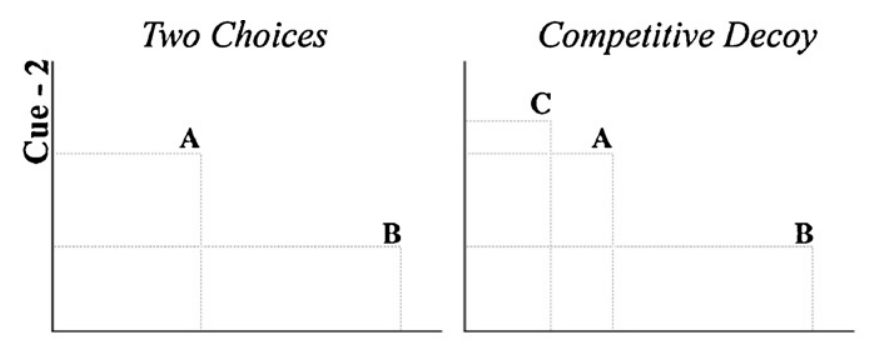

\section{Dominated Decoy}
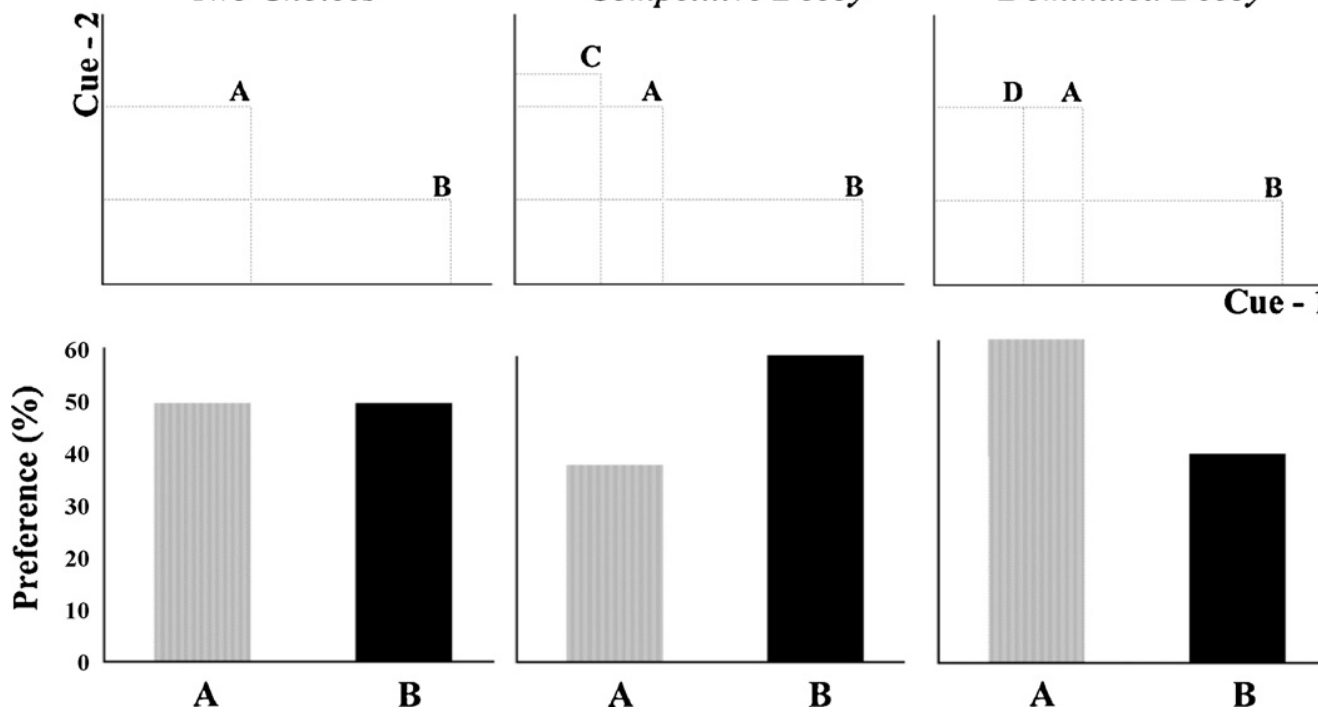

A

B

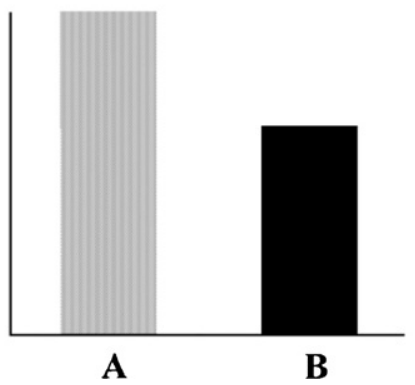

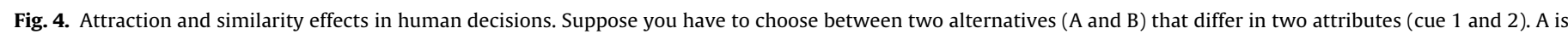

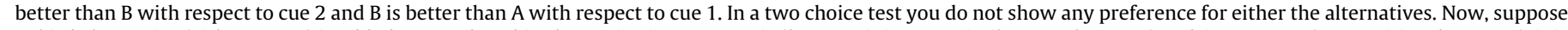

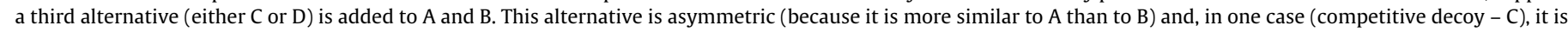

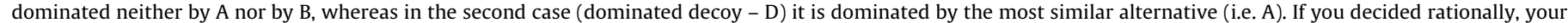

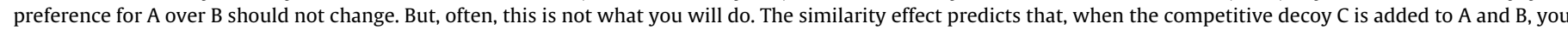

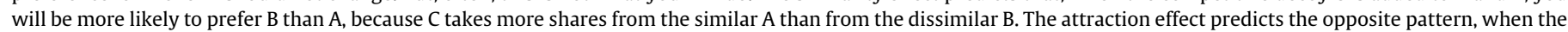

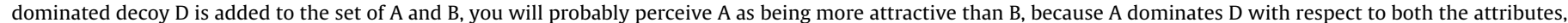
whereas $\mathrm{B}$ dominates $\mathrm{D}$ in only one of the two attributes.

option because it is not dominated by either A or B, and because it is much more similar to A than to $B$. As a consequence of the introduction of $\mathrm{C}$, the probability of choosing the similar A decreases much more than that of choosing the dissimilar B (Huber et al., 1982). The similarity effect explains why a company that is planning to launch a new product on the market tries to differentiate it from those already present to minimize "cannibalization" (Heath and Chatterjee, 1995). The "attraction effect" is observed when the third option is an asymmetrically dominated decoy as it is D in Fig. 4. Unlike C, in fact, D is inferior to and is dominated by A (but not by B) in both the attributes. The "attraction effect" predicts that when $\mathrm{D}$ is added to the control choice set, the probability of choosing A increases and that of choosing B decreases, thus violating both the regularity and the IIA conditions (Huber et al., 1982).

Since irrational choice has been observed in human economic decisions (Tversky and Kahneman, 1974) and in experiments of animal foraging (Bateson et al., 2003; Shafir, 1994), researchers have recently asked if females show irrational mating decisions as well (Bateson and Healy, 2005, Kirkpatrick et al., 2006). Observing departure from rational mate choice may be important for two reasons. First, irrational mate choice may have unpredictable and important evolutionary effects (Bateson and Healy, 2005; Kirkpatrick et al., 2006). Second, it may provide insights into the underlying mechanisms of mating decisions, in much the same way as visual illusions can help to understand the rules that govern visual perception (Newell, 2005).

To test violation of the regularity and the IIA conditions, Royle et al. (2008) devised a three-choice experiment on female swordtails, Xiphophorus helleri, to analyse the effect of asymmetrically dominated decoys on two male characters, subjected to strong directional female preferences: body size and sword size. In twochoice tests, females did not show significant overall preference for either large-body or long-sword males. When a third male (the asymmetrically-dominated decoy) was added to the set, females did change their preferences, but in a direction opposite to that predicted by the "attraction effect". In fact, the introduction of a body-size decoy increased the preference for the long-sword male, whereas the introduction of a sword decoy increased the preference for the large-size male. These results suggested that the third alternative acted as a competitive rather than dominated option, because the pattern observed was consistent with the "similarity" rather than with the "attraction effect". Royle et al. (2008) explained their results as the effect of the preference for the rare-phenotype (Eakley and Houde, 2004; Kokko et al., 2007), a pattern that has been observed also in other choice contexts (Waite, 2008).

At the moment, we do not know how common is irrational mate choice (Ryan et al., 2009). Fuller and Johnson (2009) found no support for a rare male mating advantage in bluefin killifish, Lucania goodei. Kirkpatrick et al. (2006) rejected the hypothesis that female Túngara frogs used strict mating preferences, but found no evidence for intransitive mate choice. Reaney (2009) found no clear evidence for an attraction effect in female fiddler crabs, Uca mjobergi. But suppose we found that females sometime chose irrationally, what would be the implications of this finding on mating decision models?

Departure from the principles of economic rationality is often assumed as evidence for comparative evaluation of multiple attribute options (Bateson and Healy, 2005). But our sequentialsampling models show that there are two different ways in which comparison can be carried out. In race models, comparison is indirect, because evidence for each option accumulates on different DVs, without interaction. In random-walk (tug-of-war) models, comparison is direct, because DVs are determined by the betweenoption interaction. Both the race and diffusion models as well as the Bayesian sequential model, however, predict rational choice and cannot explain either the attraction or the similarity effects. Irrational choice, thus, is not coherent with our (as well as most of) models of choice. To explain these phenomena within the theoretical framework of sequential sampling models, Roe et al. (2001) introduce the concept of lateral inhibition between multi-attribute alternatives. In this model, the options are assumed to inhibit each other proportionally to their perceived similarity. In much the same 
way as lateral inhibition in perception enhances visual edges, the model assumes that "similarity" inhibition between alternatives reinforces the perceived difference between otherwise very similar options. According to this hypothesis, departures from rational choice are not the effect of cognitive constraints, but rather the sideeffects of mechanisms that evolved to improve accuracy in decision making (Castellano, 2009a).

\section{Conclusions}

In this paper, we have proposed a thesis, derived a hypothesis, and tested it. Our thesis is that mate choice is the outcome of information processing mechanisms that can be formally explained by what Marr (1982) called a "computational theory". Our hypothesis is that the computational theory of mate choice is a Bayesian integration of evidence over time. In a certain way, our review is a first attempt of testing this hypothesis.

Our approach is similar to what cognitive psychologists know as the "rational" analysis of behaviour and cognition (Chater et al., 2003), because it assumes that, if the cognitive machinery has evolved to achieve a goal in a certain environment, then it can be described as approximating the optimal solution to achieve that goal in that environment (Chater et al., 2003). In behavioural ecology a similar approach has been adopted by students of foraging behaviour and it resulted in the formulation of the optimal foraging theory (Stephens and Krebs, 1986). In sexual selection and in mate choice, an alternative approach has prevailed. It emphasises the role of ecological constraints and focuses on the "algorithms" (the rules) rather than on the "computational theory" of mating decisions. In much the same way as, in cognitive psychology, the "fast-andfrugal' heuristics try to explain human judgment (Gigerenzer and Goldstein, 1996; Gigerenzer and Todd, 1999), in behavioural ecology, the normative models of mate choice (i.e. best-of- $n$, sequential search rules) try to explain female mate choice as a set of adaptive tools that evolved under different selective pressures and cognitive constraints. Our central argument is that these heuristics can be ascribed to a unique decisional mechanism, that we hypothesize to be the Bayesian integrator.

We highlight three main reasons why our computational model of mate choice may deserve considerations by both the theoretical and empirical research in mate choice. First, it has solid biological bases. According to 'Bayesian coding hypothesis' (Knill and Pouget, 2004), neurons code information about sensory uncertainty in the form of probability distributions, suggesting that computations underlying perception and decision making may be appropriately described by Bayesian processes. Recent studies in neuroeconomics (Glimcher, 2005) provide evidence that decisions in simple choice tasks can be predicted by the differential firing rates of neurons coding for different actions (Smith and Ratcliff, 2004), a dynamic that can be properly described by the sequential sampling models we present here and which have been used by mathematical psychologists to explain human decisions (Bogacz, 2007; Churchland et al., 2008; Gold and Shadlen, 2007; Ratcliff, 2001).

Second, it is a comprehensive model because it can explain several aspects of mate choice, such as the use of private and public information, the role of choosiness and plasticity, the accuracyspeed tradeoffs in mating decisions, aspects that have been rarely considered within a unitary theoretical framework. Third, it allows to make predictions both on the proximate mechanisms and ultimate causes of mate choice. For example, the model may be used to predict the effects of the number of alternatives on mating preferences (in terms of both strength and response time), it may be used to test the hypothesis of rational mate choice and to understand the mechanisms responsible for irrational choice. The model can be used to analyse costs, benefits and optimality of mating decisions and departures from optimal mating decisions may provide insights into the evolutionary role of ecological and cognitive constraints. In conclusion, we think this model may be useful to students that try to integrate mechanisms and functions in the study of mate choice (McNamara and Houston, 2009).

\section{References}

Akre, K.L., Ryan, M.J., 2010. Complexity increases working memory for mating signals. Curr. Biol. 20, 502-505.

Amlacher, J., Dugatkin, L.A., 2005. Preference for older over younger models during mate-choice copying in young guppies. Ethol. Ecol. Evol. 17, 161-169.

Andersson, M., 1994. Sexual Selection. Princeton University Press, Princeton, NJ.

Arak, A., 1988. Female mate selection in the natterjack toad - active choice or passive attraction. Behav. Ecol. Sociobiol. 22, 317-327.

Bailey, N.W., 2008. Love will tear you apart: different components of female choice exert contrasting selection pressures on male field crickets. Behav. Ecol. 19, 960-966.

Bailey, N.W., Zuk, M., 2008. Acoustic experience shapes female mate choice in field crickets. Proc. R. Soc. B-Biol. Sci. 275, 2645-3265.

Bailey, N.W., Zuk, M., 2009. Field crickets change mating preferences using remembered social information. Biol. Lett. 5, 449-451.

Bateman, P.W., Gilson, L.N., Ferguson, J.W.H., 2001. Male size and sequential mate preference in the cricket Gryllus bimaculatus. Anim. Behav. 61, 631-637.

Bateson, M., Healy, S.D., 2005. Comparative evaluation and its implications for mate choice. Trends Ecol. Evol. 20, 659-664.

Bateson, M., Healy, S.D., Hurly, T.A., 2003. Context-dependent foraging decisions in rufous hummingbirds. Proc. R. Soc. Lond. Ser. B: Biol. Sci. 270, 1271-2127.

Bateson, M., Kacelnik, A., 1995. Preferences for fixed and variable food sources variability in amount and delay. J. Exp. Anal. Behav. 63, 313-329.

Beckers, O.M., Wagner, W.E., 2011. Mate sampling strategy in a field cricket: evidence for a fixed threshold strategy with last chance option. Anim. Behav. 81 519-527.

Bentsen, C.L., Hunt, J., Jennions, M.D., Brooks, R., 2006. Complex multivariate sexual selection on male acoustic signaling in a wild population of Teleogryllus commodus. Am. Natur. 167, E102-E116.

Berniker, M., Körding, K., 2011. Bayesian approach to sensory integration for motor control. Cogn. Sci. 2, 419-428.

Biernaskie, J.M., Walker, S.C., Gegear, R.J., 2009. Bumblebees learn to forage like Bayesians. Am. Natur. 174, 413-423.

Bogacz, R., 2007. Optimal decision-making theories: linking neurobiology with behaviour. Trends Cogn. Sci. 11, 118-125.

Bonnie, K.E., Earley, R.L., 2007. Expanding the scope for social information use. Anim. Behav. 74, 171-181.

Booksmythe, I., Detto, T., Backwell, P.R.Y., 2008. Female fiddler crabs settle for less the travel costs of mate choice. Anim. Behav. 76, 1775-1781.

Borgia, G., 1993. The cost of display in the non-resource-based mating system of the satin bowerbird. Am. Natur. 141, 729-743.

Bosch, J., Rand, A.S., Ryan, M.J., 2000. Signal variation and call preferences for whine frequency in the tungara frog, Physalaemus pustulosus. Behav. Ecol. Sociobiol. 49 62-66.

Brandt, R., Macdonald, D.W., 2011. To know him is to love him? Familiarity and female preference in the harvest mouse, Micromys minutes. Anim. Behav. 82, 353-358.

Brandt, L.S.E., Ludwar, B.C., Greenfield, M.D., 2005. Co-occurrence of preference functions and acceptance thresholds in female choice: mate discrimination in the lesser wax moth. Ethology 111, 609-625.

Bro-Jorgensen, J., 2010. Dynamics of multiple signalling systems: animal communication in a world in flux. Trends Ecol. Evol. 25, 292-300.

Brooks, R., 1996. Copying and the repeatability of mate choice. Behav. Ecol. Sociobiol 39, 323-329.

Brooks, R., Endler, J.A., 2001. Female guppies agree to differ: phenotypic and genetic variation in mate-choice behavior and the consequences for sexual selection. Evolution 55, 1644-1655.

Brooks, R., Hunt, J., Blows, M.W., Smith, M.J., Bussiere, L.F., Jennions, M.D., 2005. Experimental evidence for multivariate stabilizing sexual selection. Evolution 59, 871-880.

Burke, E.J., Murphy, C.G., 2007. How female barking treefrogs, Hyla gratiosa, use multiple call characteristics to select a mate. Anim. Behav. 74, 1463-1472.

Burley, N.T., Foster, V.S., 2006. Variation in female choice of mates: condition influences selectivity. Anim. Behav. 72, 713-719.

Busemeyer, J.R., Jessup, R.K., Johnson, J.G., Townsend, J.T., 2006. Building bridges between neural models and complex decision making behaviour. Neural Networks 19, 1047-1058.

Bush, S.L., Gerhardt, H.C., Schul, J., 2002. Pattern recognition and call preferences in treefrogs (Anura: Hylidae): a quantitative analysis using a no-choice paradigm. Anim. Behav. 63, 7-14

Byers, J.A., Wiseman, P.A., Jones, L., Roffe, T.J., 2005. A large cost of female mate sampling in pronghorn. Am. Natur. 166, 661-668.

Calkins, J.D., Burley, N.T., 2003. Mate choice for multiple ornaments in the California quail, Callipepla californica. Anim. Behav. 65, 69-81.

Candolin, U., 2003. The use of multiple cues in mate choice. Biol. Rev. 78, 575-595.

Castellano, S., 2009a. Towards an information-processing theory of mate choice. Anim. Behav. 78, 1493-1497. 
Castellano, S., 2009b. Unreliable preferences, reliable choice and sexual selection in leks. Anim. Behav. 77, 225-232.

Castellano, S., 2010. The computational mechanisms of mate choice. Ethology 116, 283-291.

Castellano, S., Cermelli, P., 2006. Reconciling sexual selection to species recognition: a process-based model of mating decision. J. Theor. Biol. 242, 529-538.

Castellano, S., Cermelli, P., 2011. Sampling and assessment accuracy in mate choice: a random-walk model of information processing in mating decision. J. Theor. Biol. 274, 161-169.

Castellano, S., Rosso, A., 2007. Female preferences for multiple attributes in the acoustic signals of the Italian treefrog, Hyla intermedia. Behav. Ecol. Sociobiol. $61,1293-1302$

Castellano, S., Rosso, A., Giacoma, C., 2004. Active choice, passive attraction and the cognitive machinery of acoustic preferences. Anim. Behav. 68, 323-329.

Chaine, A.S., Lyon, B.E., 2008. Adaptive plasticity in female mate choice dampens sexual selection on male ornaments in the lark bunting. Science 319, 459-462.

Chater, N., Oaksford, M., Nakisa, R., Redington, M., 2003. Fast, frugal, and rational: how rational norms explain behavior. Org. Behav. Human Decision Process. 90, 63-86.

Chittka, L., Skorupski, P., Raine, N.E., 2009. Speed-accuracy tradeoffs in animal decision making. Trends Ecol. Evol. 24, 400-407.

Churchland, A.K., Kiani, R., Shadlen, M.N., 2008. Decision-making with multiple alternatives. Nat. Neurosci. 11, 693-702.

Clutton-Brock, T., McAuliffe, K., 2009. Female mate choice in mammals. Quart. Rev. Biol. 84, 3-27.

Collins, E.J., McNamara, J.M., Ramsey, D.M., 2006. Learning rules for optimal selection in a varying environment: mate choice revisited. Behav. Ecol. 17, 799-809.

Collins, S.A., 1995. The effect of recent experience on female choice in zebra finches. Anim. Behav. 49, 479-486.

Cummings, M., Mollaghan, D., 2006. Repeatability and consistency of female preference behaviours in a northern swordtail, Xiphophorus nigrensis. Anim. Behav. 72, 217-224.

Dale, S., Rinden, H., Slagsvold, T., 1992. Competition for a mate restricts mate search of female pied flycatchers. Behav. Ecol. Sociobiol. 30, 165-176.

Dale, S., Slagsvold, T., 1996. Mate choice on multiple cues, decision rules and sampling strategies in female pied flycatchers. Behaviour 133, 903-944.

Deneve, S., 2009. Bayesian decision making in two-alternative forced choices. In: Dreher, J.C., Tremblay, L. (Eds.), Handbook of Reward and Decision Making. Academic Press, London, pp. 441-458.

Doherty, J.A., 1985. Phonotaxis in the cricket, Gryllus bimaculatus DeGeer: comparisons of choice and no-choice paradigms. J. Compar. Physiol. A 157, 279-289.

Dombrovsky, Y., Perrin, N., 1994. On adaptive search and optimal stopping in sequential mate choice. Am. Natur. 144, 355-361.

Doutrelant, C., McGregor, P.K., 2000. Eavesdropping and mate choice in female fighting fish. Behaviour 137, 1655-1669.

Dugatkin, L.A., Godin, J.G.J., 1992. Reversal of female mate choice by copying in the guppy (Poecilia reticulata). Proc. R. Soc. Lond. Ser. B: Biol. Sci. 249, 179-218.

Dugatkin, L.A., Godin, J.G.J., 1993. Female mate copying in the guppy (Poecilia reticulata) - age-dependent effects. Behav. Ecol. 4, 289-292.

Dugatkin, L.A., 1996. Copying and mate choice. In: Heyes, C.M., Galef Jr, B.G. (Eds.), Social Learning in Animals: The Roots of Culture. Academic Press, San Diego, pp. 85-106.

Eakley, A.L., Houde, A.E., 2004. Possible role of female discrimination against 'redundant' males in the evolution of colour pattern polymorphism in guppies. Proc. R. Soc. Lond. Ser. B: Biol. Sci. 271, S299-S330.

Eraly, D., Hendrickx, F., Lens, L., 2009. Condition-dependent mate choice and its implications for population differentiation in the wolf spider Pirata piraticus. Behav. Ecol. 20, 856-863.

Fawcett, T.W., Johnstone, R.A., 2003a. Mate choice in the face of costly competition. Behav. Ecol. 14, 771-779.

Fawcett, T.W., Johnstone, R.A., 2003b. Optimal assessment of multiple cues. Proc. R. Soc. Lond. Ser. B: Biol. Sci. 270, 1637-2164.

Ferretti, F., Sforzi, A., Lovari, S., 2011. Behavioural interference between ungulate species: roe are not on velvet with fallow deer. Behav. Ecol. Sociobiol. 65, $875-887$.

Fisher, H.S., Rosenthal, G.G., 2006. Hungry females show stronger mating preferences. Behav. Ecol. 17, 979-981.

Fiske, P., Kalas, J.A., 1995. Mate sampling and copulation behavior of great snipe females. Anim. Behav. 49, 209-219.

Forsgren, E., 1992. Predation risk affects mate choice in a gobiid fish. Am. Natur. 140, 1041-1049.

Forsgren, E., 1997. Mate sampling in a population of sand gobies. Anim. Behav. 53, 267-276.

Friedl, T.W.P., Klump, G.M., 2005. Sexual selection in the lek-breeding European treefrog: body size, chorus attendance, random mating and good genes. Anim. Behav. 70, 1141-1154.

Fuller, R.C., Johnson, A.M., 2009. A test for negative frequency-dependent mating success as a function of male colour pattern in the bluefin killifish. Biol. J. Linnean Soc. $98,489-500$.

Gabor, C.R., Halliday, T.R., 1997. Sequential mate choice by multiply mating smooth newts: females become more choosy. Behav. Ecol. 8, 162-166.

Galef, B.G., Lim, T.C.W., Gilbert, G.S., 2008. Evidence of mate choice copying in Norway rats, Rattus norvegicus. Anim. Behav. 75, 1117-1123.

Galef, B.G., White, D.J., 2000. Evidence of social effects on mate choice in vertebrates. Behav. Process. 51, 167-175.
Galef Jr., B.G., 2006. Theoretical and empirical approaches to understanding when animals use socially acquired information and from whom they acquire it. In: Lucas, J.R., Simmons, L.W. (Eds.), Essays in Animal Behaviour: Celebrating 50 Years of Animal Behaviour. Academic Press, San Diego, California, pp. 161-182.

Gerhardt, H.C., 1991. Female mate choice in treefogs - static and dynamic acoustic criteria. Anim. Behav. 42, 615-635.

Gerhardt, H.C., Brooks, R., 2009. Experimental analysis of multivariate female choice in gray treefrogs (Hyla versicolor): evidence for directional and stabilizing selection. Evolution 63, 2504-2512.

Gerhardt, H.C., 1992. Multiple messages in acoustic signals. Semin. Neurosci. 4, $391-400$.

Gerhardt, H.C., 1995. Phonotaxis in female frogs and toads: execution and design of experiments. In: Klump, G.M., Dooling, R.J., Fay, R.R., Stebbins, W.C. (Eds.), Methods in Comparative Psychoacoustics. Birkhauser-Verlag, Basle, pp. 209-220.

Gerhardt, H.C., Huber, F., 2002. Acoustic Communication in Insects and Anurans. Chicago University Press, Chicago.

Gibson, R.M., 1996. Female choice in sage grouse: the roles of attraction and active comparison. Behav. Ecol. Sociobiol. 39, 55-59.

Gibson, R.M., Langen, T.A., 1996. How do animals choose their mates? Trends Ecol. Evol. 11, 468-470.

Gigerenzer, G., Goldstein, D.G., 1996. Reasoning the fast and frugal way: models of bounded rationality. Psychol. Rev. 103, 650-669.

Gigerenzer, G., Todd, M.P., the ABC Research group, 1999. Simple heuristics that make us smart. Oxford University Press., Oxford, UK.

Glimcher, P.W., 2005. Decisions, Uncertainty, and the Brain. MIT Press, Cambridge, MA.

Godin, J.G.J., Briggs, S.E., 1996. Female mate choice under predation risk in the guppy. Anim. Behav. 51, 117-130.

Godin, J.G.J., Herdman, E.J.E., Dugatkin, L.A., 2005. Social influences on female mate choice in the guppy, Poecilia reticulata: generalized and repeatable trait-copying behaviour. Anim. Behav. 69, 999-1005.

Gold, J.I., Shadlen, M.N., 2007. The neural basis of decision making. Ann. Rev. Neurosci. 30, 535-574.

Gong, A., Gibson, R.M., 1996. Reversal of a female preference after visual exposure to a predator in the guppy, Poecilia reticulata. Anim. Behav. 52, 1007-1015.

Grafe, T.U., 1997. Costs and benefits of mate choice in the lek-breeding reed frog, Hyperolius marmoratus. Anim. Behav. 53, 1103-1117.

Gualla, F., Cermelli, P., Castellano, S., 2008. Is there a role for amplifiers in sexual selection? J. Theor. Biol. 252, 255-271.

Heath, T.B., Chatterjee, S., 1995. Asymmetric decoy effects on lower-quality versus higher-quality brands: meta-analytic and experimental evidence. J. Consum. Res. 22, 268-284

Hebets, E.A., 2003. Subadult experience influences adult mate choice in an arthropod: exposed female wolf spiders prefer males of a familiar phenotype. Proc. Natl. Acad. Sci. U.S.A. 100, 13390-13395.

Hebets, E.A., Papaj, D.R., 2005. Complex signal function: developing a framework of testable hypotheses. Behav. Ecol. Sociobiol. 57, 197-214.

Heuschele, J., Mannerla, M., Gienapp, P., Candolin, U., 2009. Environment-dependent use of mate choice cues in sticklebacks. Behav. Ecol. 20, 1223-1227.

Hohenlohe, P.A., Arnold, S.J., 2010. Dimensionality of mate choice, sexual isolation, and speciation. Proc. Natl. Acad. Sci. U.S.A. 107, 16583-16588.

Hoi, H., Griggio, M., 2011. Is female mate preference based on the interaction between static and dynamic signals in bearded reedlings? Ethol. Ecol. Evol. 23, 171-178.

Houston, A.I., McNamara, J.M., Steer, M.D., 2007a. Do we expect natural selection to produce rational behaviour? Philos. Trans. R. Soc. B: Biol. Sci. 362 , 1531-1543.

Houston, A.I., McNamara, J.M., Steer, M.D., 2007b. Violations of transitivity under fitness maximization. Biol. Lett. 3, 365-367.

Hovi, M. Ratti, O., 1994. Mate sampling and assessment procedures in female pied flycatchers (Ficedula hypoleuca). Ethology 96, 127-137.

Huber, J., Payne, J.W., Puto, C., 1982. Adding asymmetrically dominated alternatives: violations of regularity and similarity hypothesis. J. Consum. Res. 9, 90-98.

Hutchinson, J.M.C., Gigerenzer, G., 2005. Simple heuristics and rules of thumb: where psychologists and behavioural biologists might meet. Behav. Process. 69, 97-124.

Izzo, A.S., Gray, D.A., 2011. Heterospecific courtship and sequential mate choice in sister species of field crickets. Anim. Behav. 81, 259-264.

Janetos, A.C., 1980. Strategies of female mate choice: a theoretical analysis. Behav. Ecol. Sociobiol. 7, 107-112.

Jennions, M.D., Petrie, M., 1997. Variation in mate choice and mating preferences: a review of causes and consequences. Biol. Rev. Camb. Philos. Soc. 72, 283-327.

Johnstone, R.A., 1994. Honest signaling, perceptual error and the evolution of all-ornothing displays. Proc. R. Soc. Lond. Ser. B: Biol. Sci. 256, 169-217.

Johnstone, R.A., 1996. Multiple displays in animal communication: 'backup signals' and 'multiple messages'. Philos. Trans. R. Soc. Lond. Ser. B: Biol. Sci. 351, 329-338.

Johnstone, R.A., Grafen, A., 1992. Error-prone signaling. Proc. R. Soc. Lond. Ser. B: Biol. Sci. 248, 229-323.

Kacelnik, A., 2006. Meanings of rationality. In: Nudds, M., Hurley, S. (Eds.), Rational Animals? Oxford University Press, Oxford, pp. 87-106.

Kacelnik, A., Vasconcelos, M. Monteiro, T. Aw, J., 2011. Darwin's tug-of-war vs. starlings' horse-racing: how adaptations for sequential encounters drive simultaneous choice. Behav. Ecol. Sociobiol. 65, 547-558.

Karino, K., Shimada, Y., Kudo, H., Sato, A., 2010. Relative importance of the area and intensity of the orange spots of male guppies Poecilia reticulata as mating traits preferred by females. J. Fish Biol. 77, 299-307. 
Kirkpatrick, M., Dugatkin, L.A., 1994. Sexual selection and the evolutionary effects of copying mate choice. Behav. Ecol. Sociobiol. 34, 443-449.

Kirkpatrick, M., Rand, A.S., Ryan, M.J., 2006. Mate choice rules in animals. Anim. Behav. 71, 1215-1225.

Kirkpatrick, M., Ravigne, V., 2002. Speciation by natural and sexual selection: models and experiments. Am. Natur. 159, S22-S35.

Knill, D.C., Pouget, A., 2004. The Bayesian brain: the role of uncertainty in neural coding and computation. Trends Neurosci. 27, 712-719.

Kodric-Brown, A., Nicoletto, P.F., 2001. Age and experience affect female choice in the guppy (Poecilia reticulata). Am. Natur. 157, 316-323.

Kokko, H., Jennions, M.D., Houde, A., 2007. Evolution of frequency-dependent mate choice: keeping up with fashion trends. Proc. R. Soc. Lond. Ser. B: Biol. Sci. 274, 1317-2132.

Körding, K., 2007. Decision theory: what should the nervous system do? Science $318,606-610$.

Kunzler, R., Bakker, T.C.M., 2001. Female preferences for single and combined traits in computer animated stickleback males. Behav. Ecol. 12, 681-685.

Lande, R., 1981. Models of speciation by sexual selection on polygenic traits. Proc. Natl. Acad. Sci. U.S.A. 78, 3721-3725.

Lange, A., Dukas, R., 2009. Bayesian approximations and extensions: optimal decisions for small brains and possibly big ones too. J. Theor. Biol. 259, 503-516.

Lee, M.D., Cummins, T.D.R., 2004. Evidence accumulation in decision making: unifying the take the best and the rational models. Psychon. Bull. Rev. 11, 343-352.

Lehmann, G.U.C., 2007. Density-dependent plasticity of sequential mate choice in a bushcricket (Orthoptera: Tettigoniidae). Aust. J. Zool. 55, $123-130$.

Leonard, A.S., Hedrick, A.V., 2010. Long-distance signals influence assessment of close range mating displays in the field cricket, Gryllus integer. Biol. J. Linnean Soc. $100,856-865$.

Little, A.C., Burriss, R.P., Jones, B.C., DeBruine, L.M., Caldwell, C.A., 2008. Social influence in human face preference: men and women are influenced more for long-term than short-term attractiveness decisions. Evol. Human Behav. 29, $140-146$.

Luce, R.D., 1986. Response times: Their Role in Inferring Elementary Mental Organization. Oxford Psychology Series, 8, Oxford University Press, Oxford.

Ludwig, S.C., Becker, P.H., 2008. Supply and demand: causes and consequences of assortative mating in common terns Sterna hirundo. Behav. Ecol. Sociobiol. 62, 1601-1611.

Luttbeg, B., 1996. A comparative Bayes tactic for mate assessment and choice. Behav. Ecol. 7, 451-460.

Luttbeg, B., 2002. Assessing the robustness and optimality of alternative decision rules with varying assumptions. Anim. Behav. 63, 805-814.

Luttbeg, B., Langen, T.A., 2004. Comparing alternative models to empirical data: cognitive models of western scrub-jay foraging behavior. Am. Natur. 163, 263-276.

Lynch, K.S., Crews, D., Ryan, M.J., Wilczynski, W., 2006. Hormonal state influences aspects of female mate choice in the tungara frog (Physalaemus pustulosus). Horm. Behav. 49, 450-457.

Lynch, K.S., Rand, A.S., Ryan, M.J., Wilczynski, W., 2005. Plasticity in female mate choice associated with changing reproductive states. Anim. Behav. 69, 689-699.

Mabry, K.E., Stamps, J.A., 2008. Searching for a new home: decision making by dispersing brush mice. Am. Natur. 172, 625-634.

MacLaren, R.D., Rowland, W.J., 2006. Differences in female preference for male body size in Poecilia latipinna using simultaneous versus sequential stimulus presentation designs. Behaviour 143, 273-292.

Magnhagen, C., 2006. Information about an opponent can decrease aggression in male common gobies competing for nest sites. Anim. Behav. 71, 879-884.

Marr, D., 1982. Vision. MIT Press, Cambridge, MA.

Mazalov, V., Perrin, N., Dombrovsky, Y., 1996. Adaptive search and information updating in sequential mate choice. Am. Natur. 148, 123-137.

McGregor, P., 2005. Animal Communication Networks. Cambridge University Press, Cambridge, UK.

McNamara, J.M., Green, R.F., Olsson, O., 2006. Bayes' theorem and its applications in animal behaviour. Oikos 112, 243-251.

McNamara, J.M., Houston, A.I., 2009. Integrating function and mechanism. Trends Ecol. Evol. 24, 670-675.

Mennill, D.J., Boag, P.T., Ratcliffe, L.M., 2003. The reproductive choices of eavesdropping female black-capped chickadees, Poecile atricapillus. Naturwissenschaften 90, 577-582.

Mennill, D.J., Ratcliffe, L.M., Boag, P.T., 2002. Female eavesdropping on male song contests in songbirds. Science 296, 873-873.

Mery, F., Varela, S.A.M., Danchin, E., Blanchet, S., Parejo, D., Coolen, I., Wagner, R.H., 2009. Public versus personal information for mate copying in an invertebrate. Curr. Biol. 19, 730-734.

Milner, R.N.C., Detto, T., Jennions, M.D., Backwell, P.R.Y., 2010. Experimental evidence for a seasonal shift in the strength of a female mating preference. Behav. Ecol. 21, 311-316.

Moore, A.J., Moore, P.J., 1988. Female strategy during mate choice-threshold assessment. Evolution 42, 387-391.

Moore, P.J., Moore, A.J., 2001. Reproductive aging and mating: the ticking of the biological clock in female cockroaches. Proc. Natl. Acad. Sci. U.S.A. 98, 9171-9176.

Moravec, M.L., Striedter, G.F., Burley, N.T., 2006. Assortative pairing based on contact call similarity in budgerigars, Melopsittacus undulates. Ethology 112, 1108-1116.

Moskalik, B., Uetz, G.W., 2011. Female hunger state affects mate choice of a sexually selected trait in a wolf spider. Anim. Behav. 81, 715-722.
Murphy, C.G., 2008. Assessment of distance to potential mates by female barking treefrogs (Hyla gratiosa). J. Compar. Psychol. 122, 264-273.

Murphy, C.G., Gerhardt, H.C., 2002. Mate sampling by female barking treefrogs (Hyla gratiosa). Behav. Ecol. 13, 472-480.

Naguib, M., Todt, D., 1997. Effects of dyadic vocal interactions on other conspecific receivers in nightingales. Anim. Behav. 54, 1535-1543.

Newell, B.R., 2005. Re-visions of rationality? Trends Cogn. Sci. 9, 11-15.

Nordell, S.E., Valone, T.J., 1998. Mate choice copying as public information. Ecol. Lett. $1,74-76$.

Ophir, A.G., Galef, B.G., 2004. Sexual experience can affect use of public information in mate choice. Anim. Behav. 68, 1221-1227.

Otter, K., McGregor, P.K., Terry, A.M.R., Burford, F.R.L., Peake, T.M., Dabelsteen, T., 1999. Do female great tits (Parus major) assess males by eavesdropping? A field study using interactive song playback. Proc. R. Soc. Lond. Ser. B: Biol. Sci. 266, $1305-2130$

Parker, G.A., 1978. Evolution of competitive mate searching. Ann. Rev. Entomol. 23, $173-196$.

Parker, G.A., 1982. Phenotype limited evolutionarily stable strategies. In: King's College Sociobiology Group (Eds.), Current Problems in Sociobiology. Cambridge University Press, Cambridge, pp. 173-201.

Parker, G.A., 1983. Mate quality and mating decisions. In: Bateson, P. (Ed.), Mate Choice. Cambridge University Press, Cambridge, pp. 141-164.

Partan, S., Marler, P., 1999. Behavior - communication goes multimodal. Science 283, 1272-1273.

Phelps, S.M., Rand, A.S., Ryan, M.J., 2006. A cognitive framework for mate choice and species recognition. Am. Natur. 167, 28-42.

Plath, M., Kromuszczynski, K., Tiedemann, R., 2009. Audience effect alters male but not female mating preferences. Behav. Ecol. Sociobiol. 63, 381-390.

Pleskac, T.J., Busemeyer, J.R., 2010. Two-stage dynamic signal detection: a theory of choice, decision time, and confidence. Psychol. Rev. 117, 864-901.

Poulin, R., 1994. Mate choice decisions by parasitized female upland bullies, Gobiomorphus breviceps. Proc. R. Soc. Lond. Ser. B: Biol. Sci. 256, 183-218.

Qvarnstrom, A., Part, T., Sheldon, B.C., 2000. Adaptive plasticity in mate preference linked to differences in reproductive effort. Nature 405, 344-347.

Ratcliff, R., 2001. Putting noise into neurophysiological models of simple decision making. Nat. Neurosci. 4, 336

Ratcliff, R., Smith, P.L., 2004. A comparison of sequential sampling models for twochoice reaction time. Psychol. Rev. 111, 333-367.

Real, L., 1990. Search theory and mate choice. I. Models of single-sex discrimination. Am. Natur. 136, 376-405.

Reaney, L.T., 2009. Female preference for male phenotypic traits in a fiddler crab: do females use absolute or comparative evaluation? Anim. Behav. 77, 139-143.

Rebar, D., Bailey, N.W., Zuk, M., 2009. Courtship song's role during female mate choice in the field cricket Teleogryllus oceanicus. Behav. Ecol. 20, 1307-1314.

Rebar, D., Zuk, M., Bailey, N.W., 2011. Mating experience in field crickets modifies pre- and postcopulatory female choice in parallel. Behav. Ecol. 22, 303-309.

Reboreda, J.C., Kacelnik, A., 1991. Risk sensitivity in starlings - variability in food amount and food delay. Behav. Ecol. 2, 301-308.

Reid, M.L., Stamps, J.A., 1997. Female mate choice tactics in a resource-based mating system: field tests of alternative models. Am. Natur. 150, 98-121.

Riebel, K., 2003. The mute sex revisited: vocal production and perception learning in female songbirds. Adv. Stud. Behav. 33, 49-86.

Riebel, K., 2009. Song and female mate choice in zebra finches: a review. Adv. Stud. Behav. 40, 197-238.

Roe, R.M., Busemeyer, J.R., Townsend, J.T., 2001. Multi-alternative decision field theory: a dynamic connectionist model of decision-making. Psychol. Rev. 108, 370-392.

Royle, N.J., Lindstrom, J., Metcalfe, N.B., 2008. Context-dependent mate choice in relation to social composition in green swordtails Xiphophorus helleri. Behav. Ecol. 19, 998-1005.

Ryan, M.J., Akre, K.L., Kirkpatrick, M., 2007. Mate choice. Curr. Biol. 17, R313-R316.

Ryan, M.J., Rand, A.S., 1993. Species recognition and sexual selection as a unitary problem in animal communication. Evolution 47, 647-657.

Ryan, M.J., 1997. Sexual selection and mate choice. In: Krebs, J.R., Davies, N.B. (Eds.), Behavioural Ecology, An Evolutionary Approach, Fourth edition. Blackwell, Oxford, pp. 179-202.

Ryan, M.J., 2001. Anuran Communication. Smithsonian Institution Press, Washington.

Ryan, M.J., Akre, K.L., Kirkpatrick, M., 2009. Cognitive mate choice. In: Dukas, R. Ratcliffe, J. (Eds.), Cognitive Ecology II. University of Chicago Press, Chicago, pp. 137-155.

Scheffer, S.J., Uetz, G.W., Stratton, G.E., 1996. Sexual selection, male morphology, and the efficacy of courtship signalling in two wolf spiders (Araneae: Lycosidae) Behav. Ecol. Sociobiol. 38, 17-23.

Scheuber, H., Jacot, A., Brinkhof, M.W.G., 2004. Female preference for multiple condition-dependent components of a sexually selected signal. Proc. R. Soc. Lond. Ser. B: Biol. Sci. 271, 2453-3245.

Schielzeth, H., Bolund, E., Forstmeier, W., 2010. Heritability of and early environment effects on variation in mating preferences. Evolution 64, 998-1006.

Schlupp, I., Ryan, M.J., 1997. Male sailfin mollies (Poecilia latipinna) copy the mate choice of other males. Behav. Ecol. 8, 104-107.

Schnupp, J.W.H., King, A.J., 2001. Neural processing: the logic of multiplication in single neurons. Curr. Biol. 11, R640-R642.

Schul, J., Bush, S.L., 2002. Non-parallel coevolution of sender and receiver in the acoustic communication system of treefrogs. Proc. R. Soc. Lond. Ser. B: Biol. Sci. 269, 1847-2185. 
Schwartz, J.J., Huth, K., Hutchin, T., 2004. How long do females really listen? Assessment time for female mate choice in the grey treefrog, Hyla versicolor. Anim. Behav. 68, 533-540.

Shackleton, M.A., Jennions, M.D., Hunt, J., 2005. Fighting success and attractiveness as predictors of male mating success in the black field cricket, Teleogryllus commodus: the effectiveness of no-choice tests. Behav. Ecol. Sociobiol. 58, $1-8$.

Shafir, S., 1994. Intransitivity of preferences in honey-bees support for comparativeevaluation of foraging options. Anim. Behav. 48, 55-67.

Shapiro, M.S., Siller, S., Kacelnik, A., 2008. Simultaneous and sequential choice as a function of reward delay and magnitude: normative, descriptive and processbased models tested in the European starling (Sturnus vulgaris). J. Exp. Psychol.: Anim. Behav. Process. 34, 75-93.

Sirot, E., 2001. Mate-choice copying by females: the advantages of a prudent strategy. J. Evol. Biol. 14, 418-423.

Slagsvold, T., Lifjeld, J.T., Stenmark, G., Breiehagen, T., 1988. On the cost of searching for a mate in female pied flycatchers Ficedula hypoleuca. Anim. Behav. 36 433-442.

Smith, P.L., Ratcliff, R., 2004. Psychology and neurobiology of simple decisions. Trends Neurosci. 27, 161-168.

Stephens, D.W., Krebs, J.R., 1986. Foraging Theory. Princeton University Press, Princeton, NJ.

Sullivan, M.S., 1994. Mate choice as an information gathering process under time constraint - implications for behavior and signal-design. Anim. Behav. 47, $141-151$.

Swaddle, J.P., Cathey, M.G., Correll, M., Hodkinson, B.P., 2005. Socially transmitted mate preferences in a monogamous bird: a non-genetic mechanism of sexual selection. Proc. R. Soc. Lond. B: Biol. Sci. 272, 1053-1105.

Tai, F.D., Wang, T.Z., Zhao, Y.J., 2000. Inbreeding avoidance and mate choice in the mandarin vole (Microtus mandarinus). Can. J. Zool.: Rev. Can. Zool. 78 2119-2125.

Trimmer, P.C., Houston, A.I., Marshall, J.A.R, Bogacz, R., Paul, E.S., Mendl, M.T. McNamara, J.M., 2008. Mammalian choices: combining fast-but-inaccurate and slow-but-accurate decision-making systems. Proc. R. Soc. Lond. Ser. B: Biol. Sci. $275,2353-3236$

Tversky, A., Kahneman, D., 1974. Judgment under uncertainty: heuristics and biases. Science 185, 1124-1131.

Uehara, T., Yokomizo, H., Iwasa, Y., 2005. Mate-choice copying as Bayesian decision making. Am. Natur. 165, 403-410.

Uy, J.A.C., Patricelli, G.L., Borgia, G., 2000. Dynamic mate-searching tactic allows female satin bowerbirds Ptilonorhynchus violaceus to reduce searching. Proc. R. Soc. Lond. Ser. B: Biol. Sci. 267, 251-325.

Valone, T.J., 1989. Group foraging, public information, and patch estimation. Oikos $56,357-363$

Valone, T.J., 2006. Are animals capable of Bayesian updating? An empirical review. Oikos 112, 252-259.
Valone, T.J., 2007. From eavesdropping on performance to copying the behavior of others: a review of public information use. Behav. Ecol. Sociobiol. 62, 1-14.

Valone, T.J., Nordell, S.E., Giraldeau, L.A., Templeton, J.J., 1996. The empirical question of thresholds and mechanisms of mate choice. Evol. Ecol. 10, 447-455.

Valone, T.J., Templeton, J.J., 2002. Public information for the assessment of quality: a widespread social phenomenon. Philos. Trans. R. Soc. Lond. Ser. B: Biol. Sci. 357 1549-1557.

Vasconcelos, M., Monteiro, T., Aw, J., Kacelnik, A., 2010. Choice in multi-alternative environments: a trial-by-trial implementation of the sequential choice model Behav. Process. 84, 435-439.

Wagner, W.E., 1998. Measuring female mating preferences. Anim. Behav, 55 1029-1042.

Wagner, W.E., Basolo, A.L., 2007. The relative importance of different direct benefits in the mate choices of a field cricket. Evolution 61, 617-622.

Wagner, W.E., Smeds, M.R., Wiegmann, D.D., 2001. Experience affects female responses to male song in the variable field cricket Gryllus lineaticeps (Orthoptera Gryllidae). Ethology 107, 769-776.

Waite, T.A., 2008. Preference for oddity: uniqueness heuristic or hierarchical choice process? Anim. Cogn. 11, 707-713.

Walling, C.A., Royle, N.J., Lindstrom, J., Metcalfe, N.B., 2010. Do female association preferences predict the likelihood of reproduction? Behav. Ecol. Sociobiol. 64 541-548.

Westneat, D.F., Walters, A., McCarthy, T.M., Hatch, M.I., Hein, W.K., 2000. Alternative mechanisms of nonindependent mate choice. Anim. Behav. 59, 467-476.

White, D.J., Galef, B.G., 2000. 'Culture' in quail: social influences on mate choices of female Coturnix japonica. Anim. Behav. 59, 975-979.

Widemo, F., Saether, S.A., 1999. Beauty is in the eye of the beholder: causes and consequences of variation in mating preferences. Trends Ecol. Evol. 14, 26-31.

Widemo, M.S., 2006. Male but not female pipefish copy mate choice. Behav. Ecol. 17, 255-259.

Wiegmann, D.D., Angeloni, L.M., 2007. Mate choice and uncertainty in the decision process. J. Theor. Biol. 249, 654-666.

Wiegmann, D.D., Seubert, S.M., Wade, G.A., 2010a. Mate choice and optimal search behavior: fitness returns under the fixed sample and sequential search strategies. J. Theor. Biol. 262, 596-600.

Wiegmann, D.D., Weinersmith, K.L., Seubert, S.M., 2010b. Multi-attribute mate choice decisions and uncertainty in the decision process: a generalized sequential search strategy. J. Math. Biol. 60, 543-572.

Witte, K., 2006. Learning and mate choice. In: Brown, C., Laland, K., Krause, J. (Eds.) Fish Cognition and Behavior. Blackwell Publishing Ltd., Oxford, pp. 70-95.

Witte, K., Ueding, K., 2003. Sailfin molly females (Poecilia latipinna) copy the rejection of a male. Behav. Ecol. 14, 389-395.

Yang, T., Shadlen, M.N., 2007. Probabilistic reasoning by neurons. Nature 447, $1075-1080$

Zuk, M., Johnson, K., Thornhill, R., Ligon, J.D., 1990. Mechanisms of female choice in red jungle fowl. Evolution 44, 477-485. 